\title{
OPERATING MANUAL FOR THE R2O0 DOWNHOLE RECORDER WITH TANDY 102 RETRIEVER
}

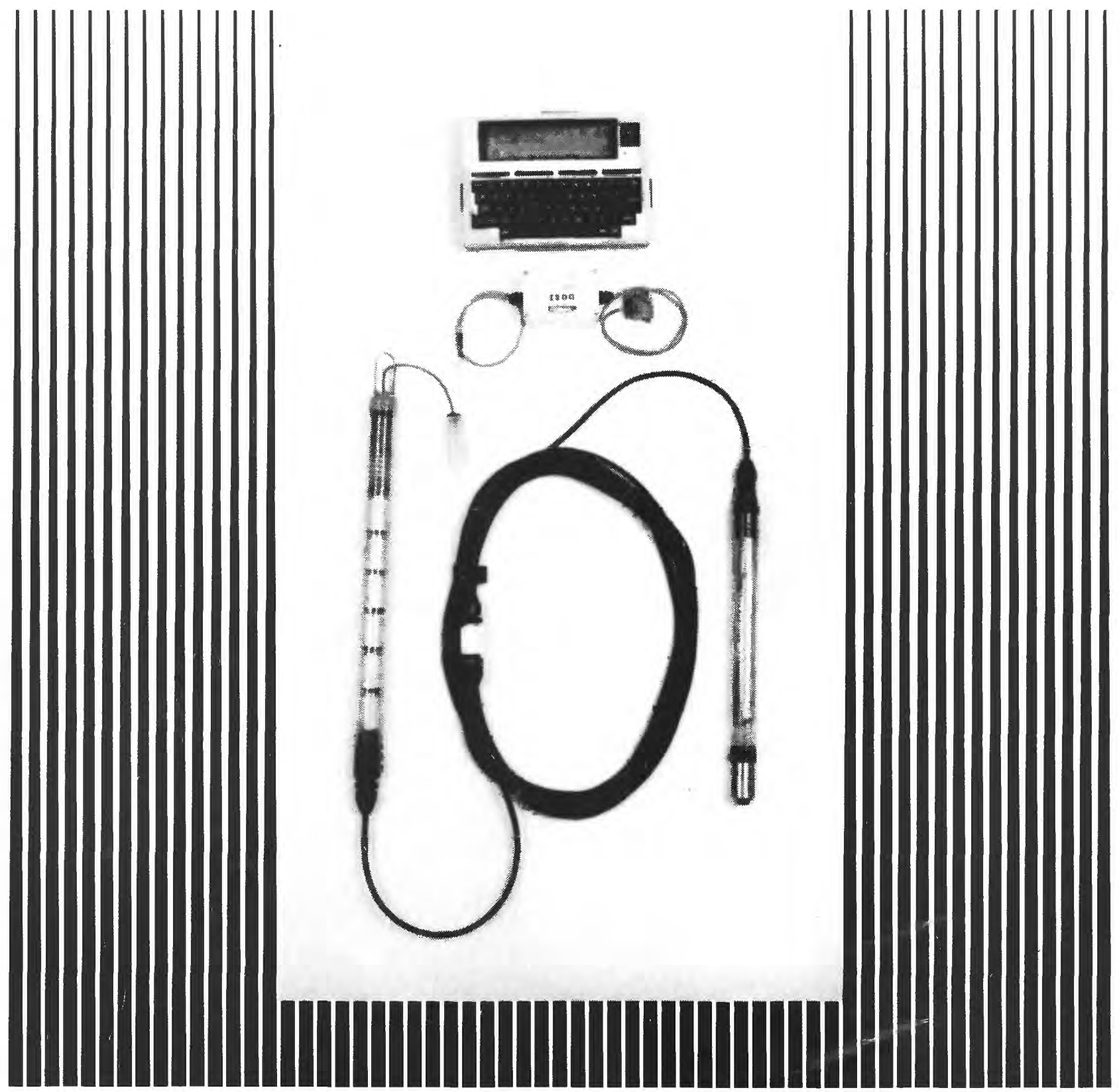

U.S. GEOLOGICAL SURVEY Open-File Report 88-488

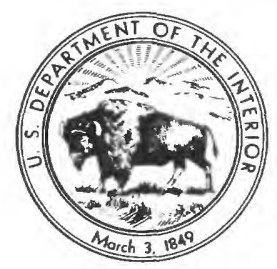




\section{CONVERSION FACTORS}

For readers who prefer to use International System (SI) units, rather than the inch-pound terms used in this report, the following conversion factors may be used:

\section{Multiply}

inch (in.)

foot ( $f t$ )

pound per square inch $\left(\mathrm{lb} / \mathrm{in}^{2}\right)$ pound (1b) by

25.4

0.3048

6.895

0.4536
To obtain

millimeter (mm) meter (m) kilopascal ( $\mathrm{kPa}$ ) kilogram (kg)

Temperature

degree Fahrenheit $\left({ }^{\circ} \mathrm{F}\right) \quad{ }^{\circ} \mathrm{C}=5 / 9 \times\left({ }^{\circ} \mathrm{F}-32\right) \quad$ degree Celsius $\left({ }^{\circ} \mathrm{C}\right)$

\section{Additional Abbreviations}

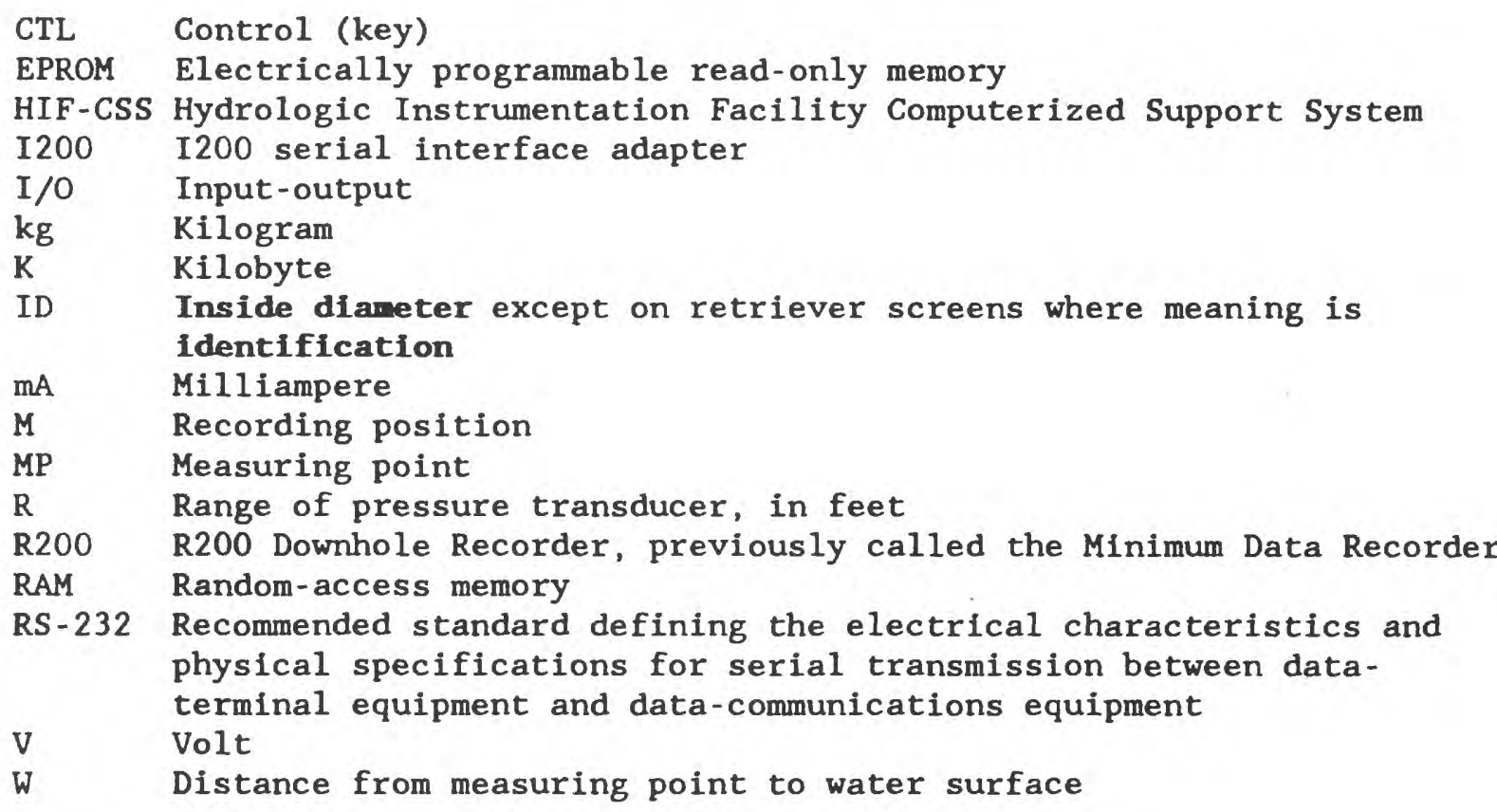

PHOTO--Top center: data retriever; midcenter: I200 serial interface adapter; left: battery holder; right: probe. 
OPERATING MANUAL FOR THE R200 DOWNHOLE RECORDER

WITH TANDY 102 RETRIEVER

By Roy A. Johnson and James I. Rorabaugh

U.S . GEOLOGICAL SURVEY

Open-File Report 88-488

Stennis Space Center, Mississippi

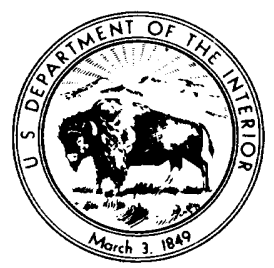




\section{DEPARTMENT OF THE INTERIOR \\ DONALD PAUL HODEL, Secretary}

U.S. GEOLOGICAL SURVEY

Dallas L. Peck, Director

For additional information, write to:

Chief

Hydrologic Instrumentation Facility U.S. Geological Survey, WRD Building 2101

Stennis Space Center, MS 39529
Copies of this report can

be purchased from:

U.S. Geological Survey Books and Open-File Reports Section Federal Center

Box 25425

Denver, Colorado 80225 


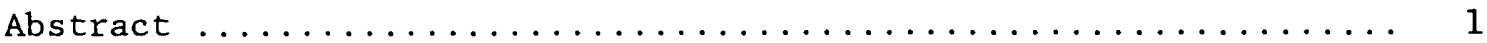

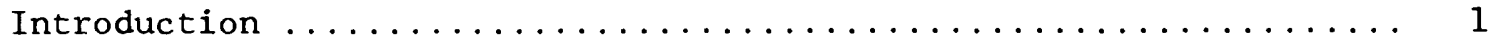

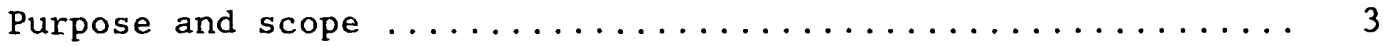

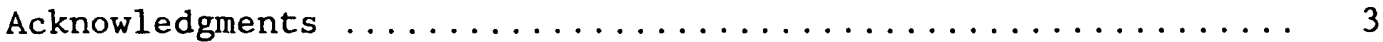

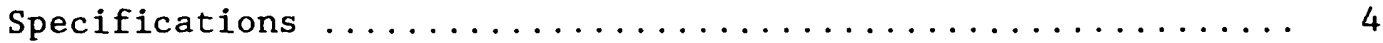

Initial setup of the R200 Downhole Recorder .............. 5

Suspension of the R200 in a well .................. 5

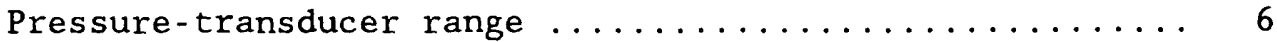

Battery-pack cable ....................... 8

Worksheet for selection of transducer range and battery-

pack cable length .................... 9

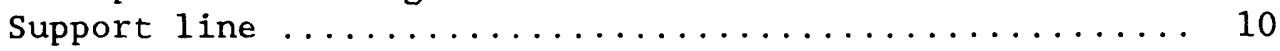

Recording position .......................... 12

Worksheet for positioning and suspension of R200 . . . 13

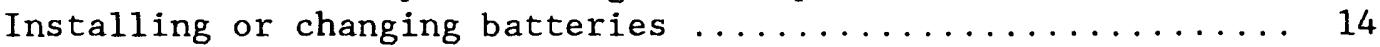

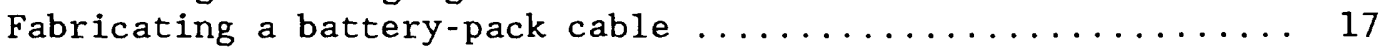

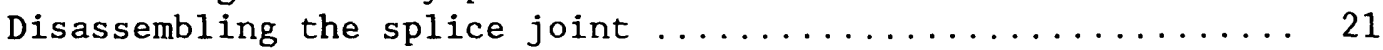

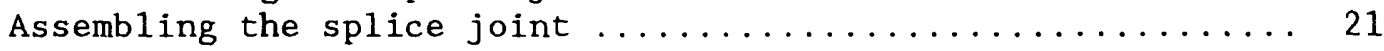

Changing the battery-pack cable ...................... 22

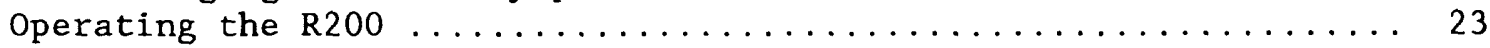

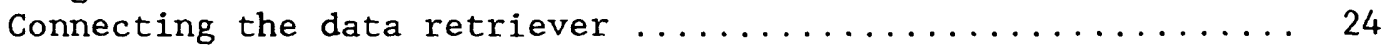

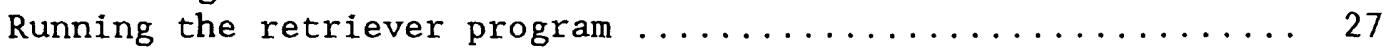

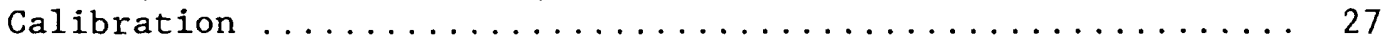

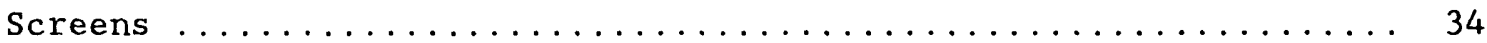

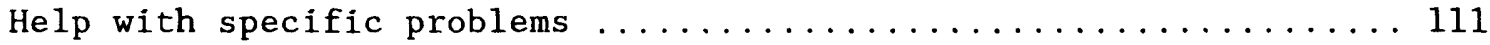

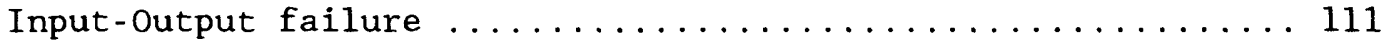

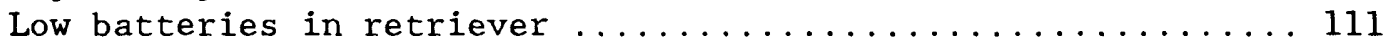

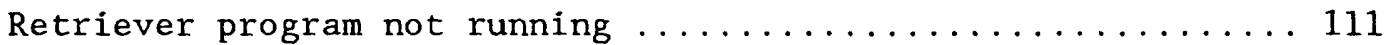

Supplement I. Ordering information $\ldots \ldots \ldots \ldots \ldots \ldots \ldots \ldots \ldots \ldots \ldots \ldots \ldots$

\section{ILLUSTRATIONS}

Figures 1-10. Diagrams showing:

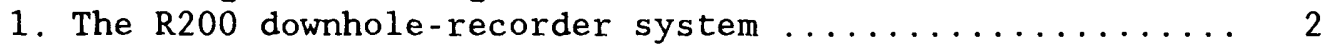

2. A typical well installation .................... 9

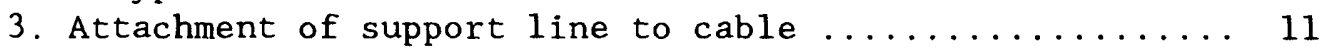

4. Positioning and suspension of the R200 in a well ..... 12

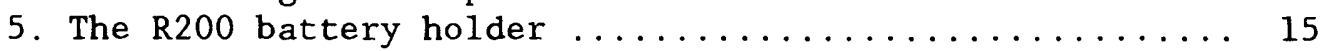

6. Fabrication of a battery-pack cable ............. 19

7. Assembled and disassembled splice joint .......... 20

8. Connection of the data retriever and $R 200 \ldots \ldots \ldots 25$

9. Use of support line for in-well calibration at the 10 -percent calibration point ............. 29

10. Achievement of 90-percent calibration-point depth using calibration cable and support line ............. 31 
Use of brand names in this report is for identification purposes only and does not constitute endorsement by the U.S. Geological Survey. 


\section{OPERATING MANUAL FOR THE R200 DOWNHOLE RECORDER WITH TANDY 102 RETRIEVER}

By Roy A. Johnson and James I. Rorabaugh

\section{ABSTRACT}

The R200 Downhole Recorder is a battery-powered device that, when placed in a well casing, monitors water levels for up to 1 year. This instrument measures a 1 - to 70 -foot range of water levels. These waterlevel data can be retrieved through use of a commercially available portable microcomputer. The R200 Downhole Recorder was developed at the U.S. Geological Survey's Hydrologic Instrumentation Facility, Stennis Space Center, Mississippi.

This operating manual describes the R200 Downhole Recorder, provides initial setup instructions, and gives directions for onsite operation. Design specifications and routine maintenance steps are included.

The R200 data-retriever program is a user-friendly, menu-driven program. The manual guides the user through the procedures required to perform specific operations. Numerous screens are reproduced in the text with a discussion of user input for desired responses. Help is provided for specific problems.

\section{INTRODUCTION}

The U.S. Geological Survey monitors water levels in thousands of observation wells. To collect the data, Survey personnel use float-driven recorders that have strip-chart or punched paper-tape output. At distances greater than 50 feet or in wells smaller than 6 inches in diameter, the float and its suspension line begin to drag on the side of the we11, causing errors in the readings or causing complete stoppage of the recorder. The surface shelter required for this method sometimes attracts vandals.

The R200 Downhole Recorder (R200), developed at the Hydrologic Instrumentation Facility (HIF), Stennis Space Center, Mississippi, was designed to improve the efficiency and effectiveness of the Survey's ground-water monitoring program. The R200 is a battery-powered, microprocessorcontrolled sensor and recorder, which operates unattended for up to 1 year and fits inside a 2 -inch borehole or casing. Figure 1 depicts the various parts of the R200 system. In use, the R200 probe section is positioned below the water surface. A pressure transducer, located in the probe section, is the water-level sensor. This pressure transducer monitors the pressure of the water above it through the pressure port on the probe section.

The pressure transducer monitors gage pressure, or the pressure of the water with respect to atmospheric pressure. This is required so that changes in atmospheric pressure do not cause the R200 to record these atmospheric pressure changes as water-level changes. All pressure measurements are referenced to atmospheric pressure through a vent tube extending through the probe cable and battery-pack cable and out through the top of the battery holder. The battery holder is positioned at the top of the well and 
contains the batteries that power the R200. At the top of the battery holder is a connector that permits connection to a commercially available, portable microcomputer. This portable computer is used to set up the R200 at the beginning of a recording period and to extract the data at the end of the recording period. A serial interface adapter, the 1200 , is used between the portable computer, called the retriever, and the R200 to allow the two devices to communicate properly.

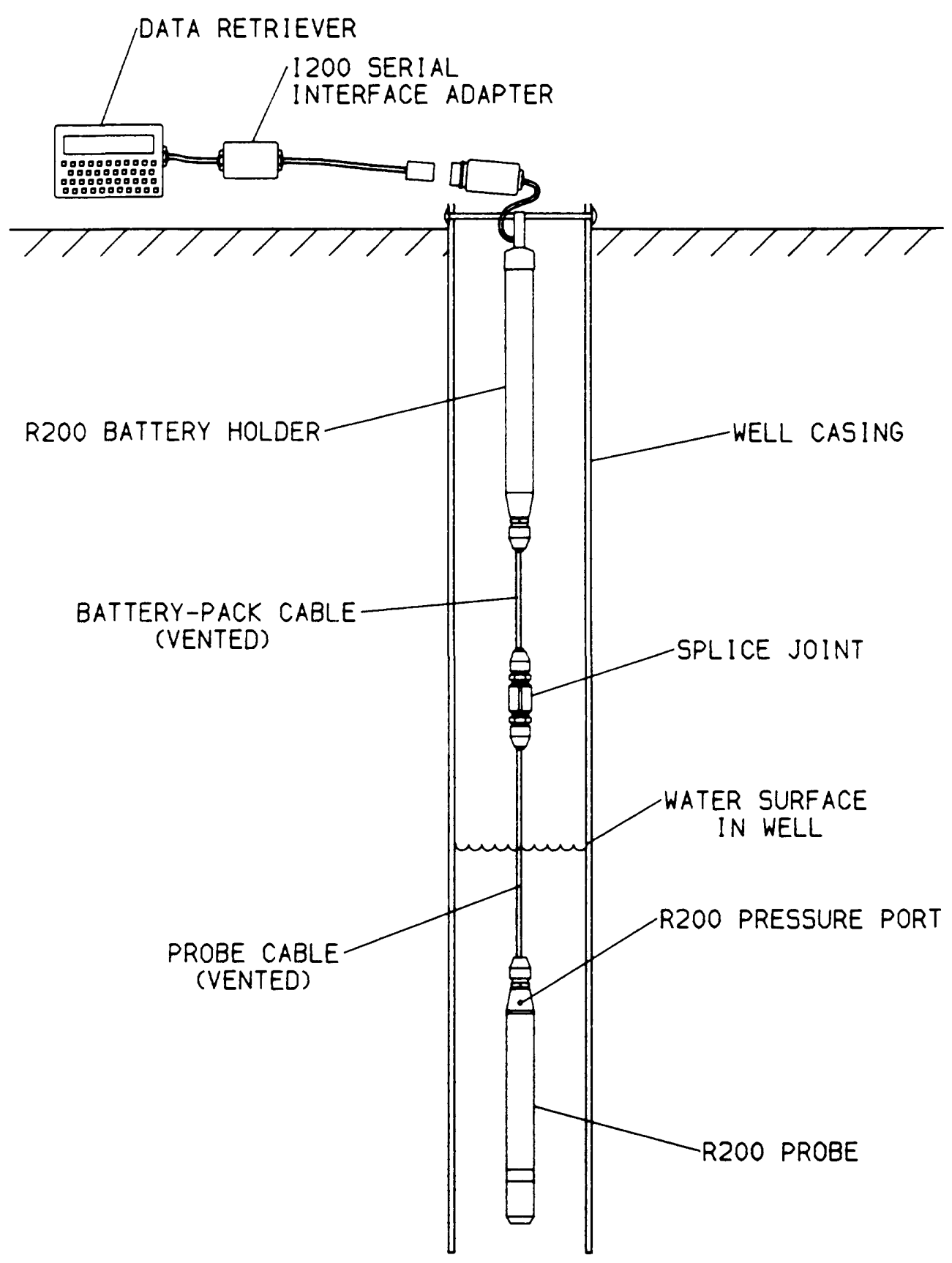

Figure 1.--The R200 Downhole-Recorder system. 
During the recording period, the R200 probe senses the water level every hour. At the end of the day, the R200 computes the average of the 24 hourly readings and records this as a data point. The $\mathrm{R} 200$ also records the time and value of the maximum and minimum hourly readings for the period of record. The R200 employs a family of pressure transducers to cover a total range of water levels from 0 to 70 feet.

\section{Purpose and Scope}

The purpose of this manual is to describe the R200 Downhole Recorder, provide initial setup instructions, and give directions for its onsite operation. The manual instructs the user in the operation of the portable microcomputer, called the data retriever, which is used for setting up the R200 and retrieving the data at the end of a recording period. Where necessary, the manufacturer's directions for the specific microcomputer used as the data retriever must be used in conjunction with this operating manual. Instructions for repair of the recorder are not included in this manual. If a problem occurs, the unit should be returned to the HIF Field Service and Supply Section for repair.

\section{Acknowledgments}

The authors acknowledge the Survey personnel in Arizona and Nebraska, who assisted in the field tests of the R200, and HIF employees W. L. Rapp and E. H. Cordes for their contributions. 


\section{Specifications}

Listed below are the design specifications of the R200 Downhole Recorder:

Installation ........... Recorder installed below the water surface in a well 2 in. ( $50 \mathrm{~mm}$ ) or larger in diameter.

Record interval .......... Senses water level each hour; records average hourly readings once each day; and records maximum and minimum readings (with time tag) for the period of record. Software can be changed for other intervals.

Memory capacity ......... 1200 readings with standard memory (2K); 5200 readings with optional memory ( $8 \mathrm{~K})$.

Pressure-transducer type ..... Semiconductor strain gage.

Pressure-transducer ranges ... 10, 15, and $301 \mathrm{~b} / \mathrm{in}^{2}$.

Pressure accuracy ........ 0.5 percent of full scale (using in-well calibration); 2 percent of full scale (using factory calibration).

Timer accuracy $\ldots \ldots \ldots \ldots \ldots \pm 4$ min each month.

Data input/output ......... Serial input line-.0 to $5 \mathrm{~V}$; serial output line.open collector, $100 \mathrm{~mA}$ maximum.

Operating temperature range.. 0 to $60{ }^{\circ} \mathrm{C}$.

Current consumption ......6. $6 \mathrm{~mA}$ operating, $120 \mu \mathrm{A}$ standby, $200 \mu \mathrm{A}$ average.

Battery type ..........6 alkaline D-cells.

Battery 1 ife ...........4 400 days.

Memory $\ldots \ldots \ldots \ldots \ldots \ldots \ldots 2 \mathrm{~K}$ or $8 \mathrm{~K}$ data storage (RAM); $4 \mathrm{~K}$ program storage (EPROM).

Microprocessor ............. Motorola 6805E2.

Probe dimensions ........21-in. (533-mm) length by $1.7-$ in. (43-mm) diameter.

Battery-holder dimensions ... 25.5-in. (648-mm) length by 1.8-in. (46-mm) diameter.

Probe weight $\ldots \ldots \ldots \ldots \ldots .2 .5 \mathrm{lb}(1.1 \mathrm{~kg})$.

Battery-holder weight $\ldots \ldots 2.81 \mathrm{~b}(1.3 \mathrm{~kg})$ with batteries. 
INITIAL SETUP OF THE R200 DOWNHOLE RECORDER

GAUTION: The pressure transducer used in the R200 is a sensitive device that can be danaged by excessive pressure. Submersing the R200 probe beyond the rated range of the pressure transducer may cause permanent damage to the transducer. Extreme care must be exercised when the R200 is removed from a well during freezing temperatures. When the R200 is submerged, the pressure port on the probe fills with water. If this water is allowed to freeze in the pressure port, permanent damage to the pressure transducer may occur. To prevent this from happening, the user should employ the following routine when removing the $\mathrm{R} 200$ from a well during freezing conditions:

1. Hold the R200 probe upside down and shake all remaining water out of the pressure-port opening.

2. Fill the pressure-port opening with alcohol and allow it to remain for several seconds.

3. Again hold the R200 probe upside down and shake all of the alcohol out of the pressure-port opening.

4. Repeat steps 2 and 3 above.

The alcohol acts as an antifreeze when mixed with any water remaining in the port. Failure to perform this task in freezing conditions may result in damage to the pressure transducer, requiring that the $\mathrm{R} 200$ be shipped to the HIF Field Service and Supply Section for repair.

NOTE: The pressure port on the probe should be cleaned and freed of any mud or debris each time the well is visited or each time the R200 is removed from a well. To clean out the pressure port, the probe should be held upside down and the pressure port flushed VERY GENTLY with water. DO NOT INSERT ANY OBJECTS OR TOOLS INTO THE PRESSURE PORT. Do not use any powerful stream of water when flushing out the pressure port--only a very gentle flow of water.

\section{Suspension of the R200 in a Well}

The $\mathrm{R} 200$ can be suspended in a well in a variety of ways. The suspension methods outlined in this manual were found to work well during the initial field tests of the R200 conducted in Arizona and Nebraska.

Note the following considerations when suspending the R200 in a we11: Water-level data recorded in the R200 is measured through the pressure port on the R200 probe; therefore, the position of this port must be accurately known and must remain stationary throughout the recording period. The line or cable used to suspend the R200 in a well should have a very limited potential for stretch. The line or cable should be graduated with markings that have a maximum cumulative error of \pm 0.05 foot. 
The R200 probe and battery holder were designed to fit inside a 2-inchID well casing. Only a vented cap may be used on the well. An additional over-the-well shelter is not needed. The cabling used on the R200 has a minimum bending radius of 3 inches. This allows the use of an excess length of battery-pack cable on the R200. Any excess cable can be coiled inside the well casing in wells with 3 -inch-diameter, or larger, casings.

A typical well installation, shown in figure 2, identifies the various parts of the R200 and the hardware used for suspending the recorder in the we11. The part of the R200 that is placed under the water surface and contains the pressure transducer and electronics is called the probe. Each R200 probe is supplied with a fixed length of vented cable attached. The length of this cable depends on the pressure range of the pressure trans ducer in the R200. An R200 with a 23-foot range has 31 feet of cable on the probe. A 35-foot probe has 41 feet of cable and a 70 -foot probe has 76 feet of cable. This probe cable is terminated inside a splice joint, where it is connected to the battery-pack cable. The battery-pack cable connects the R200 battery pack at the top of the well to the probe cable at the splice joint. The splice joint is designed to remain above the surface of the water. Thus, the R200 probe must be positioned at a depth where the splice joint will remain above water during times of maximum water level, while the probe remains under the water during times of minimum water level. These considerations determine the battery-pack cable length.

\section{Pressure-Transducer Range}

The pressure range of an R200 is the range of pressures that the pressure transducer inside the R200 probe can monitor without damage to the transducer. Three ranges are available: 23, 35, and 70 feet of water (corresponding to 10,15 , and $30 \mathrm{lb} / \mathrm{in}^{2}$ ). The range is chosen according to the hydrologic conditions at the particular well site. For example, in a well where the difference between the absolute minimum and maximum water levels is only 10 feet, an R200 with the 23 -foot range would be more than adequate. However, if the water level in the well fluctuates as much as 50 feet, an R200 with a 70 -foot range would be needed. If the pressure transducer in the $\mathrm{R} 200$ is subjected to pressures much greater than its intended range, permanent damage to the transducer may occur.

For a quick approximation of the required transducer range for a particular well, simply determine the difference, in feet, between the yearly maximum and minimum water levels, and then increase this difference by about 10 percent. Because accuracy is a percentage of full-scale range, it is desirable to use the lowest range possible without overpressuring the pressure transducer.

The Water Resources Division (WRD) Instrumentation Catalog contains a worksheet, which aids in determining the required pressure-transducer range for a well site. A sample worksheet is included at the end of the next section, "Battery-Pack Cable." 


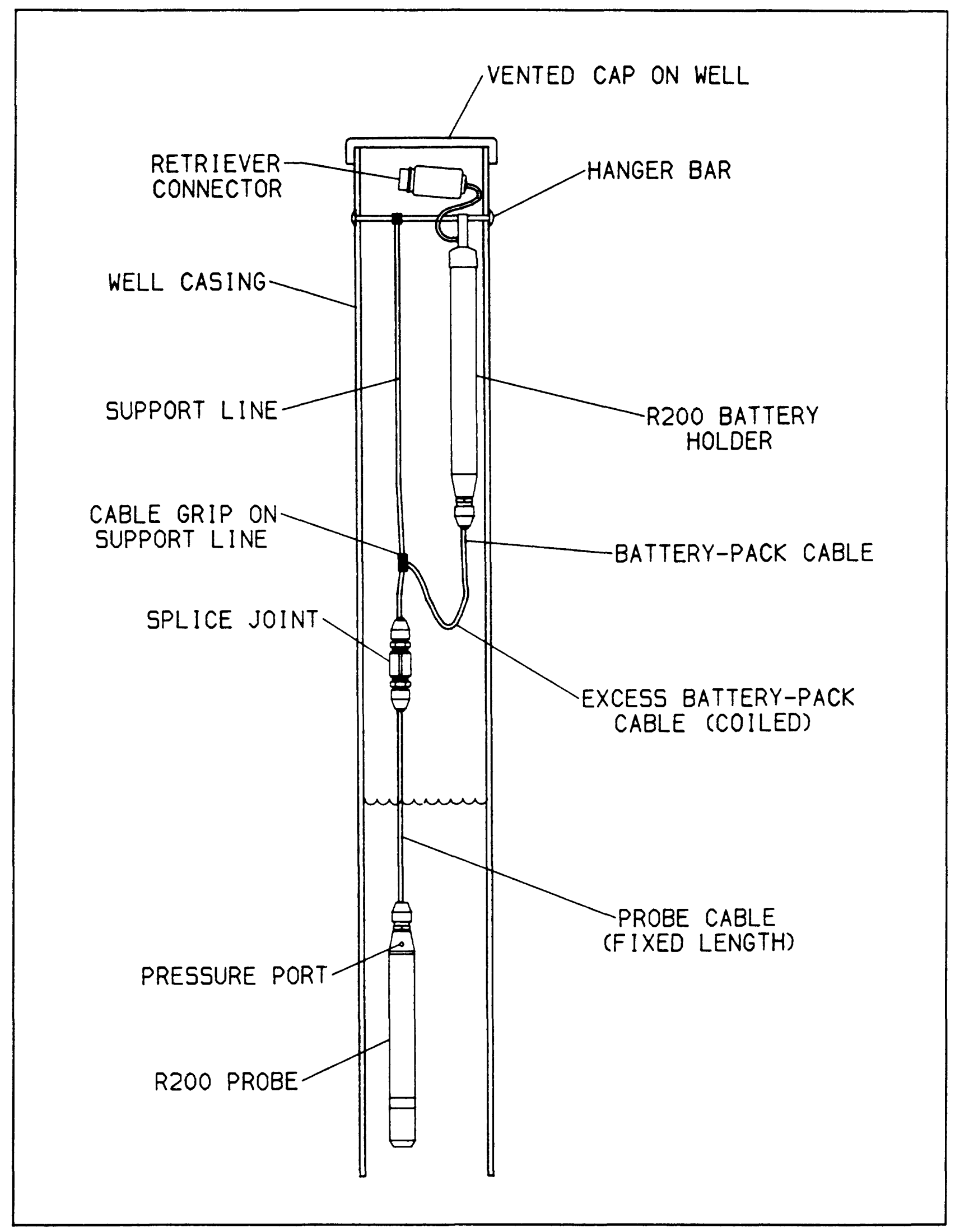

Figure 2.--A typical well installation. 


\section{Battery-Pack Cable}

A vented battery-pack cable connects the R200 battery holder at the top of the well to the probe cable at the splice joint. Since the probe cable is a fixed length, in accordance with the range of the pressure transducer in the probe, the battery-pack cable must be of a length that will place the probe in the desired position for recording. Longer battery-pack cables can be used on wells with a 3-inch-ID, or larger, casing, but a support line is then needed to hang the probe at the desired depth. The excess battery-pack cable can be coiled inside the well casing. Extra cable length may be desirable to accommodate any permanent decline of the water table over a period of time. Battery-pack cables can be ordered from HIF in lengths of $25,50,100$, or 200 feet. A custom-length cable can be made at the HIF by contacting the Chief, Field Service and Supply Section. The WRD Instrumentation Catalog contains a worksheet that will aid in determining the required battery-pack cable length and pressure-transducer range for a well site. A sample worksheet is included on the following page. 
The distance to maximum water level is the expected shortest distance from the measuring point (usually the top of the well casing) to the surface of the water in the well.

The distance to minimum water level is the expected greatest distance from the measuring point (usually the top of the well casing) to the surface of the water in the well.

1. Enter distance to minimum water level: $\mathrm{D} 1=$ ft

2. Enter distance to maximum water leve1: $\mathrm{D} 2=$ ft

3. Calculate the SPAN: $\quad$ SPAN $=\mathrm{D} 1-\mathrm{D} 2=$ ft

4. Use the SPAN to select pressure-transducer range and probe cable length:

\begin{tabular}{|c|c|c|c|}
\hline $\begin{array}{l}\text { SPAN } \\
(\mathrm{ft})\end{array}$ & $\begin{array}{l}\text { Trans } \\
1 \mathrm{~b} / \text { in }\end{array}$ & $\begin{array}{l}\text { range } \\
(\mathrm{ft})\end{array}$ & $\begin{array}{c}\text { Probe cable length } \\
\text { (ft) }\end{array}$ \\
\hline 0 to 23 & 10 & 23 & 31 \\
\hline 23 to 35 & 15 & 35 & 41 \\
\hline 35 to 70 & 30 & 70 & 76 \\
\hline
\end{tabular}

Select transducer range: $\mathrm{R}=$ ft Enter probe cable length: $P=$ ft

5. Calculate battery-pack cable length:

Battery-pack cable length $=[0.5(\mathrm{D} 1+\mathrm{D} 2+\mathrm{R})]-\mathrm{P}=\ldots \mathrm{ft}$

NOTE: Battery-pack cables are available in standard lengths of 25, 50, 100, and 200 feet. These standard-length cables can be interconnected to obtain other lengths. In wells where the well casing is 3 inches or greater in diameter, it may be desirable to order a battery-pack cable slightly longer than this calculated length (especially if the long-term water level is declining). The excess cable can be coiled and left inside the well casing. This suspension method requires the use of the support-line kit. (See WRD Instrumentation Catalog No.5105019.)

6. If ordering a custom-length battery-pack cable that matches the length calculated above, insert this length into the blank below. Otherwise, determine the actual length of battery-pack cable to be ordered (any of the standard lengths or any combination of standard lengths).

Enter actual battery-pack cable length: $\quad B=\ldots f t$

7. Using the procedure below, determine whether or not a calibration cable will be needed for this R200 at its site.

- If $(D 1+0.9 \mathrm{R})=$ $\mathrm{ft}$ is greater than $(P+B)=$ $\mathrm{ft}, \mathrm{a}$ calibration cable and support-line kit will be necessary for calibration of this R200 in its well. If $(D 1+0.9 R)$ is greater than $(P+B)$ by more than 35 feet, a 70 -foot calibration cable is required. Otherwise, a 35-foot calibration cable will suffice.

- If several R200 recorders are being operated, only one calibration cable and one support-line kit are necessary for calibration and can be used for calibrating all recorders.

- If all recorders requiring a calibration cable are being operated with their own support lines, a separate support line for use with the calibration cable is not necessary. 


\section{Support Line}

A 1/8-inch-diameter Kevlar ${ }^{1}$ support line, shown in figure 3 , is available from the HIF warehouse. The support line is used to suspend the R200 probe at the desired depth. These support lines are available in lengths of 35 and 70 feet. A cable grip on one end of the support line is used to connect the support line to the battery-pack cable. The other end of the support line is then attached to a hanger bar or some other fixed support at the top of the well to hold the R200 probe at the proper depth. The support line can be permanently marked or graduated for ease of calibration and installation of the R200. The cable grip on the support line is attached to the battery-pack cable at a premeasured position, which will allow markings on the support line to be used for positioning the probe at the recording position and at the 10-, 50-, and 90-percent calibration points.

The cable grip is attached to the battery-pack cable as follows (Refer to figure 3 ):

- The cable grip on the end of the support line is made up of two separate pieces;

- the part of the cable grip labeled "cable gripper" (in figure 3) is permanently attached to the support line;

- the other piece of the cable grip, labeled "cable-grip sliding catch" is removed from the cable grip by sliding it off the top of the cable gripper;

- the R200 battery-pack cable is then laid along the length of the cable gripper into the shallow groove;

- after the sliding catch is replaced over the battery-pack cable and onto the cable gripper, the sliding catch is pulled down securely, wedging the battery-pack cable between the two pieces of the cable grip.

The length of the support line can be adjusted by loosening the two screws in the rope clamp located at the end of the support line next to the safety hook. These screws can be loosened enough to allow the support line to be pulled through the clamp. Once the hook is repositioned at the proper point on the line, the two screws in the rope clamp must be retightened. Any excess support line can be bundled and left inside the well casing or gagehouse, or it can be cut off and discarded if not needed for future applications .

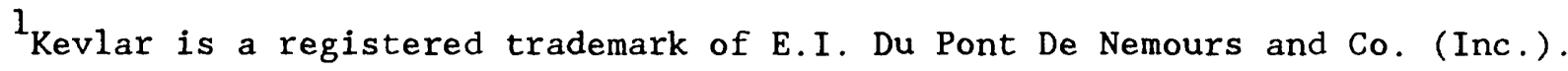




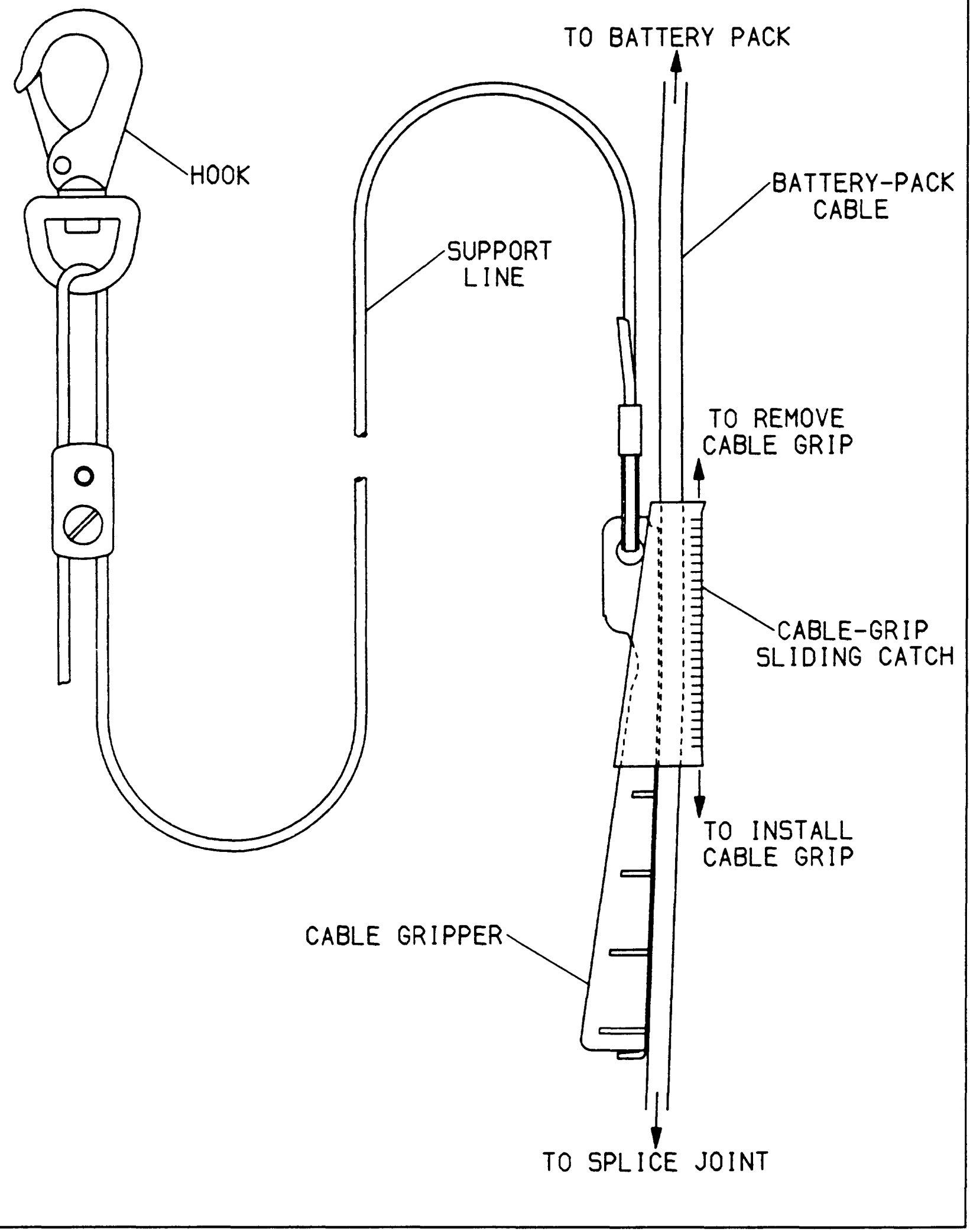

Figure 3.-Attachment of support line to cable. 
The pressure port on the $\mathrm{R} 200$ probe is the reference point for all water-level data recorded by the R200. The R200 measures the amount of water over its pressure port. Therefore, the distance from the measuring point (usually the top of the well casing) to the pressure port on the R200 probe is called the recording position and must remain fixed over the recording period. Because the probe cable (between the probe and the splice joint) is

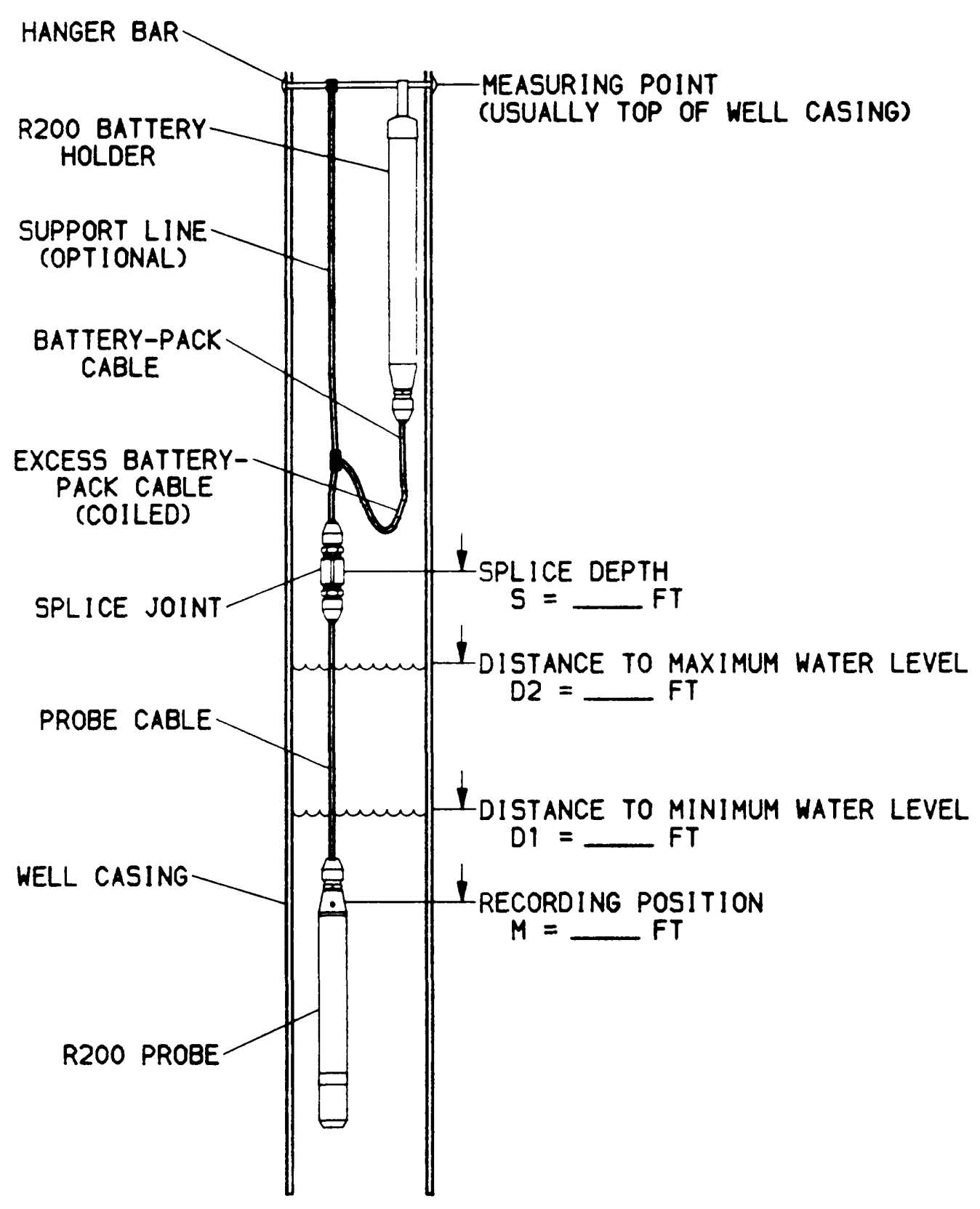

Figure 4.--Positioning and suspension of the R200 in a well. 
of a fixed length, the splice joint can be placed at a known depth that will locate the probe at the required recording position. The field person will find figure 4 and the worksheet below helpful when positioning and suspending the R200 in a we11. The worksheet is an aid in calculating the desired recording position and corresponding splice depth. After the sp1ice depth is determined, the field person can use the support line to hang the R200 with the splice located at the required depth. If the length of the battery-pack cable being used matches the splice depth closely, the support line can be left off and the battery-pack cable fully extended into the well.

\section{WORKSHEET FOR POSITIONING AND SUSPENSION OF R200}

This worksheet is used in conjunction with figure 4 to determine the positioning and suspension of the R200 recorder in a well.

1. Enter distance to minimum water leve1: $\quad$ D1 $=$ ft

2. Enter distance to maximum water level: $\mathrm{D} 2=$ ft

3. Use the pressure-transducer range of the R200 to find the corresponding probe cable length:

\begin{tabular}{lc}
$\begin{array}{l}\text { Transqucer } \\
\left(\mathrm{lb} / \mathrm{in}^{2}\right)\end{array}$ & $\begin{array}{l}\text { range } \\
\text { (ft) }\end{array}$ \\
\hline 10 & 23 \\
15 & 35 \\
30 & 70
\end{tabular}

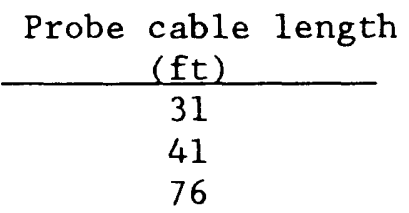

Enter the R200 transducer range: $R=$ ft

Enter the corresponding probe cable length: $\quad \mathrm{P}=\ldots$ ft

4. Calculate the recording position:

$$
M=0.5(D 1+D 2+R)=
$$
$\mathrm{ft}$

5. Calculate the splice depth:

$$
S=M-P=
$$

NOTE: If the length of the battery-pack cable being used with the R200 is very close to the calculated splice depth, the support line is not necessary, and the battery-pack cable can be fully extended into the well. However, if the length of the battery-pack cable is greater than the calculated splice depth, the support line is attached to the battery-pack cable somewhere above the splice joint. This support line is used to hang the R200 in the we 11 with the probe located at the desired recording position (or, equivalently, with the splice joint located at the desired splice depth). 


\section{Installing or Changing Batteries}

Refer to figure 5.

During the process of retrieving the data record, the retriever will indicate on screen 174 when it is time to change the batteries. Have available six D-size alkaline batteries, a screwdriver, 0-ring lubricant, new desiccant, and a supply of good quality paper towels before starting to change batteries. Refer to the cautions in the Initial Setup of the R200 Downhole-Recorder section. Figure 5 is a diagram of the battery holder. To install or change batteries, perform the following steps:

1. Wash away all dirt from the upper end of the battery holder before starting the disassembly. Locate the battery holder in a convenient work area. Be sure the probe does not contain any valuable data, as all data will be lost when the batteries are removed.

2. Slide the vinyl cover to the top of the metal bail, exposing the two screws that secure the bail.

3. Remove the two screws that secure the bail.

4. Pull the sealing plug and connector out of the battery holder. This should be done by grasping the strain-relief connector and pulling the sealing plug out of the battery holder, avoiding any pulling on the cable.

5. If the ribbon cable, attached to the bottle, strain relief, and sealing plug assembly, is long enough to allow removal of the cylindrical spacer, spring, and batteries, proceed to step 6 . Otherwise, disconnect the connector that separates the battery-holder casing (ribbon cable) from the bottle, strain relief, and sealing-plug assembly. Set this assembly aside for later reinstallation.

6. Remove the cylindrical spacer.

7. Pull the spring assembly out of the battery holder and leave it hanging by the ribbon cable. Remove the desiccant from the inside of the spring assembly.

8. Remove the old batteries.

9. Hold the now empty battery holder upside down with the open end down. Use a clean cloth to wipe the mouth of the battery holder, removing any dirt and (or) moisture.

10. Install six new D-size alkaline batteries into the tube with the positive ends of the batteries positioned toward the bottom of the tube, as indicated by the polarity decal on the battery-holder case. Check the ribbon cable to make sure it is not folded or tangled between the batteries.

11. Install new desiccant inside the spring assembly. The desiccant should be changed each time the batteries are changed. 


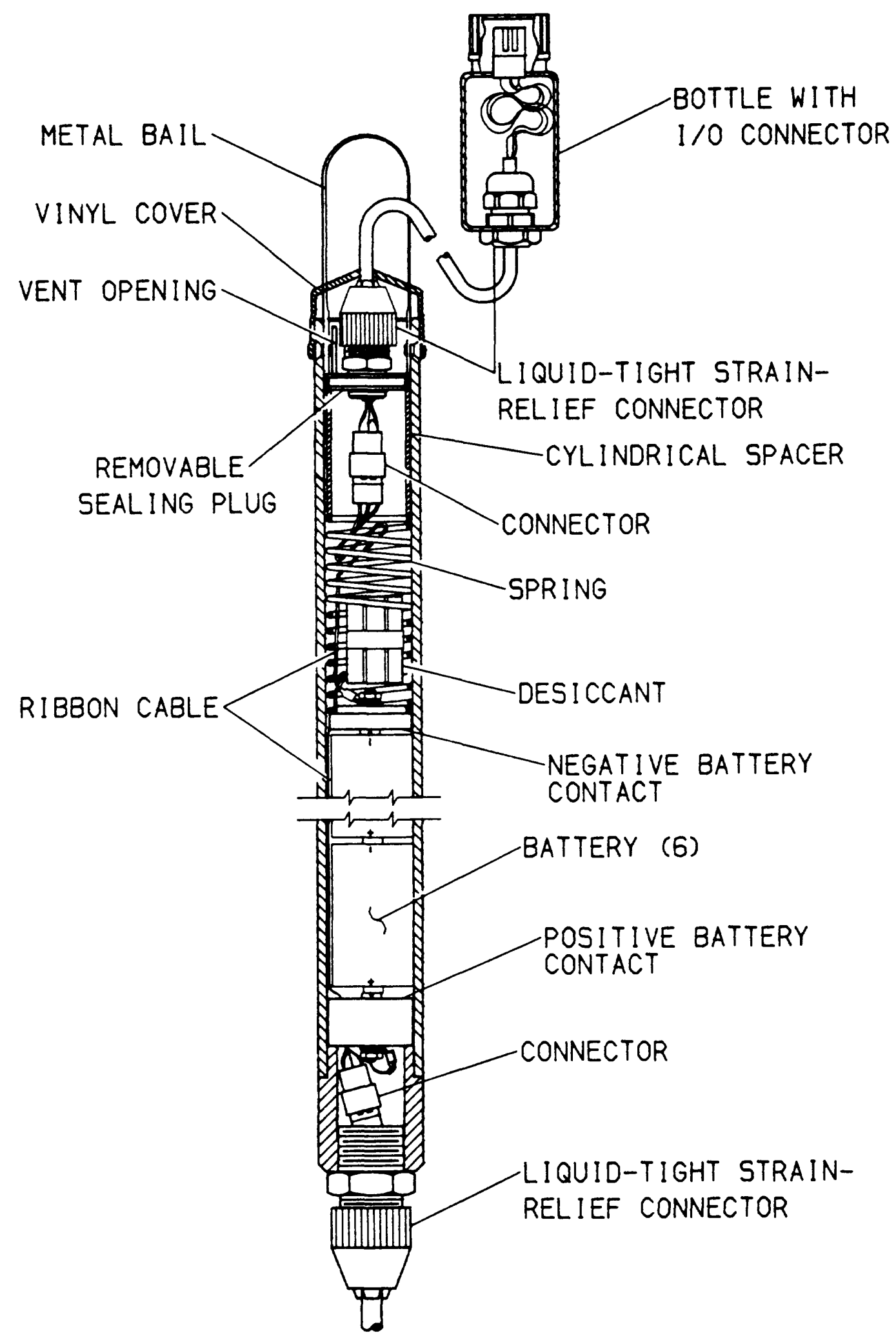

Figure 5.--The R200 battery holder. 
12. Use a cloth to remove any debris or moisture from the spring assembly.

13. Slide the spring assembly back into the battery holder until it contacts the negative side of the battery. Make sure the ribbon cable does not twist or kink.

14. Use a cloth to remove any debris or moisture from the cylindrical spacer.

15. Slide the cylindrical spacer over the connector and ribbon cable and into the battery holder.

16. Use a clean cloth to remove any debris and moisture from the bail and sealing plug. Make sure the o-ring around the sealing plug is free of dirt and moisture. CAUTION: If the o-ring is torn or twisted, it should be replaced. Apply a small amount of silicon-based 0-ring lubricant to the o-ring and the inside surface of the end of the battery holder.

17. Plug the connector on the bottle, bail, and sealing-plug assembly into the mating connector on the battery holder, if they were disconnected in step 5 .

18. Press the sealing plug into the battery holder, allowing the connectors to extend inside the cylindrical spacer.

19. Using the bail, press the sealing plug into the battery-holder casing until the screw holes on the bail align with the two screw holes nearest the end of the battery holder. Install the two screws.

\section{CAUTION:}

- Do not press on the battery-pack cable at the botton of the battery holder as sharply bending. it will kink the vent tube inside.

- When reinstalling the bail, be sure to use the screw holes nearest the top edge of the battery holder and not the drain holes, which are located farther down the battery-holder case.

- Overtightening the screws may crack the battery-holder case.

20. Slide the vinyl cover over the battery holder until it covers the two screws.

21. Connect the retriever and check for probe operation. Use screen 123 of the retriever program to check the condition of the batteries. (See section on running the retriever program.) 


\section{Fabricating a Battery-Pack Cable}

The battery-pack cable used with the R200 can be fabricated to a custom length by a user who is skilled in wire stripping and the use of crimp-on connectors. Those who are not skilled in using crimp-on connectors should contact the HIF to obtain preassembled, fixed-length, battery-pack cables or to have a custom-length cable made.

The following supplies are needed to fabricate a battery-pack cable:

- The desired length of vented cable

NOTE: This cable should be cut approximately 4 inches longer than the desired length to account for end terminations.

- Connector housings--One each of the following:

Receptacle (socket-type), 6-conductor Molex No. 03-06-1062

Plug (pin-type), 6-conductor Molex No. 02-06-2061

- Crimp terminals--Five each of the following:

Socket-type Molex No. 02-06-1103

Pin-type Molex No. 02-06-2103

- Crimping tool for above crimp terminals

(Contact Molex for the proper tool. Use of an improper tool may cause failure or intermittent operation of the R200.)

- The proper extraction tool--(Contact Molex for this tool. This will be needed if a pin or socket is inadvertently inserted in the wrong position.)

- Two liquid-tight, strain-relief connectors Thomas \& Betts part No. 2693.

- Spaghetti tubing, 0.042 -inch-ID

(Used to cover and insulate No. 18 ground wire)

- Wire stripper for No. 18 gage wire, small diagonal cutters, a small sharp knife, and a small screwdriver. 
Refer to figure 6 during the following assembly procedure:

1. Cut vented cable to desired length.

2. Slide the two 1iquid-tight, strain-reliefs onto the cable as illustrated in figure 6-A. Be sure to slide all parts of each strain relief onto the cable with the proper orientation and in the proper order. Figure 7-B shows the parts of a strain-relief being placed onto a cable.

3. Using the diagonal cutters and the knife, strip the outer covering from the vented cable, leaving the wires and vent tube protruding to the lengths shown in figure 6-B. Use care to prevent damage to the insulation on the individual wires.

4. Only the black, red, orange, yellow, and bare drain wires will be used. Cut off any other wires flush with the outer cable covering.

5. Strip $1 / 8$ inch of insulation from the black, red, orange, and yellow wires.

6. Install a piece of spaghetti tubing over the ground wire on each end of the cable, leaving $1 / 8$ inch of bare wire exposed.

7. On the end of the cable that will be terminated with the plug (male or pins), crimp a pin (Molex No. 02-06-2103) onto each of the five wires. Note that the crimp pin has two gripping points: one should grip the conductor and the other should grip the insulation.

8. Insert the pins with the attached wires into the plug (Molex No. 02-06-2061) in the positions shown in figure 6-C. The plug has numbers written on the wire side, and the color code is: 1 yellow, 2 red, 3 orange, 4 black, 5 no connection, and 6 ground wire. After insertion, test, by pulling on each wire, to be sure each pin has locked into place. If a pin does not lock into place, use a small screwdriver to press the pin firmly into the plug. If a mistake is made, an extraction tool will be necessary to remove the pin in error, or the whole connector must be cut off and thrown away.

9. On the end of the cable that will be terminated with the receptacle (female or sockets), crimp a socket (Molex No. 03-06-1062) onto each of the five wires. Note that the crimp socket has two gripping points: one grips the wire while the other grips the insulation.

10. Insert the sockets with the attached wires into the receptacle (Molex No. 03-06-1062) in the positions shown in figure 6-D. The receptacle has numbers written on the wire side, and the color code is: 1 yellow, 2 red, 3 orange, 4 black, 5 no connection, and 6 ground wire. Test, by pulling on each wire, to be sure each socket has locked into place. If a socket does not lock into place, use a small screwdriver to press the socket firmly into the receptacle.

11. The battery-pack cable is now complete and is ready to install between the battery holder and the splice joint. 


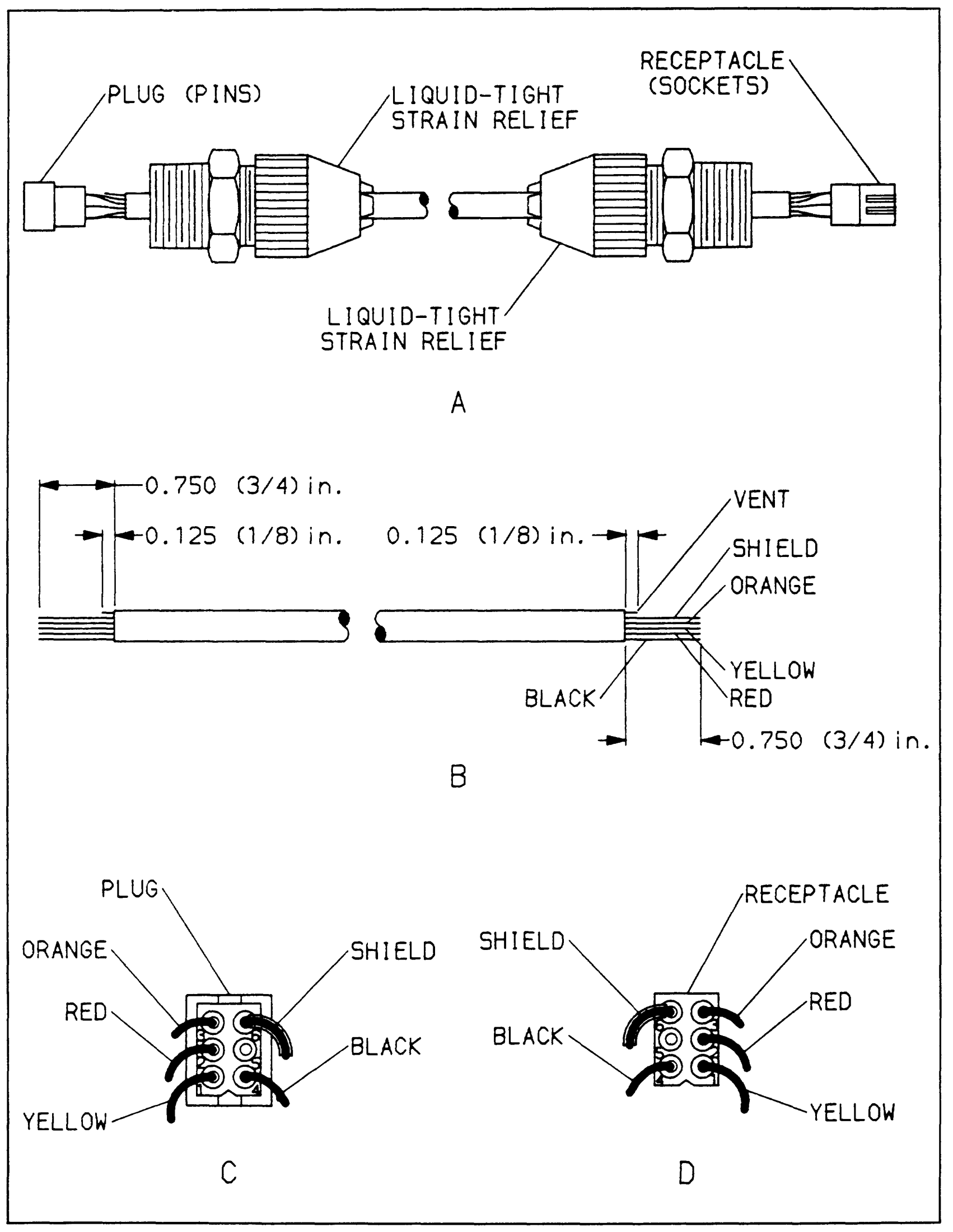

Figure 6.--Fabrication of a battery-pack cable. 


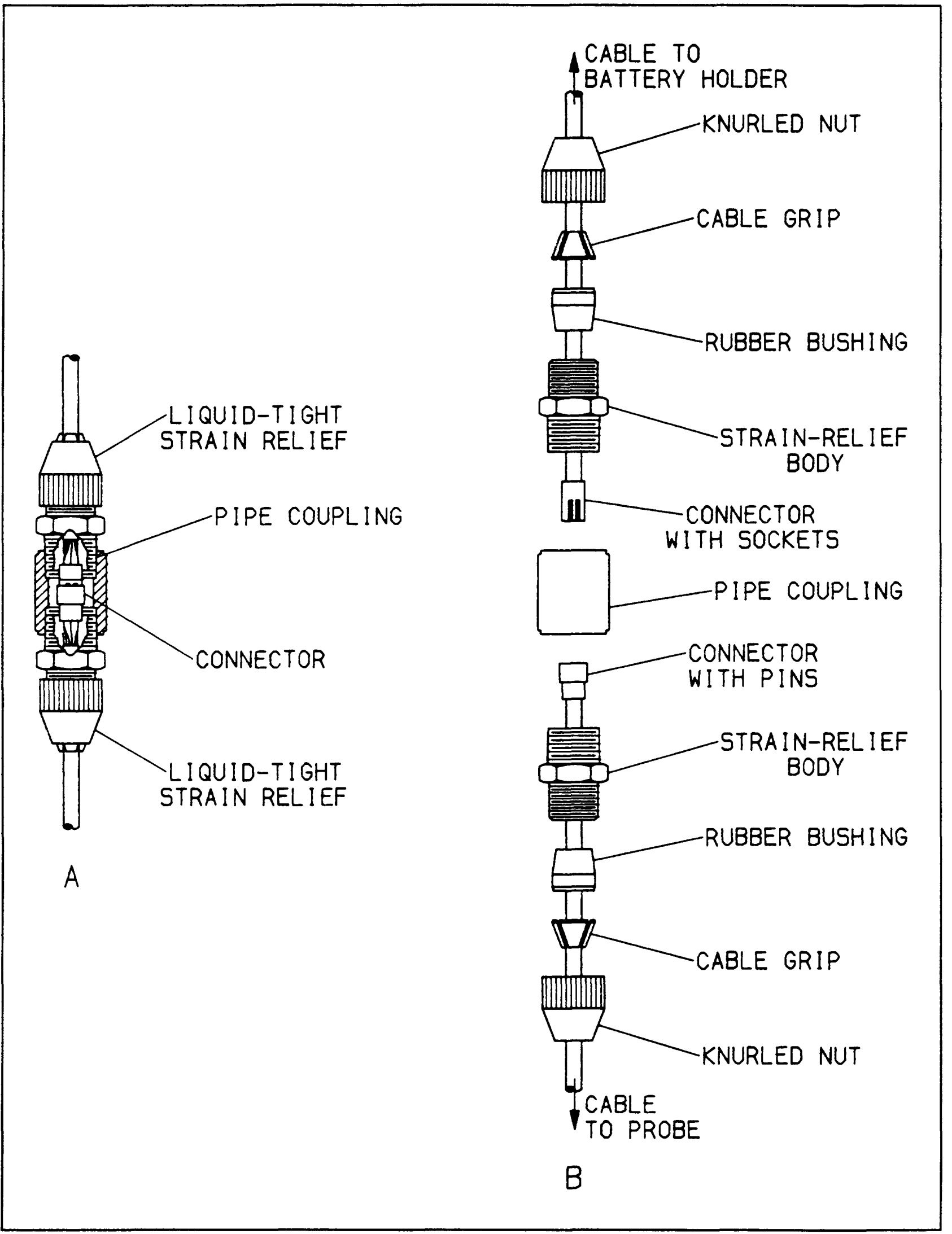

Figure 7.--Assembled and disassembled splice joint. 


\section{Disassembling the Splice Joint}

NOTE: Remove any dirt or water from the splice joint before beginning the disassembly.

Refer to figure 7 while performing the following tasks:

1. Unscrew the knurled nuts at the top and bottom of the splice joint.

2. Pull back the cable grips and rubber bushings at both ends of the splice.

3. Unscrew one of the strain-relief bodies from the pipe coupling.

4. Slide the pipe coupling down the cable to expose the connectors.

5. Unplug the six-pin connectors.

\section{Assembling the Splice Joint}

Refer to figure 7 during the assembly operation.

1. Make sure the splice is fully disassembled as described in the previous section.

2. Check the condition of the cable where the liquid-tight strain relief will grip. The cable must be smooth and free of water, grit, oil, and grease where the rubber bushing seals. The cable can be cleaned with alcohol. If the cable is rough, it must be cut and reterminated or replaced.

3. Make sure one of the strain-relief bodies is screwed into the pipe coupling. If not, apply plastic-thread joint sealant to the threads of the strain-relief body and screw it into the pipe coupling. Tighten firmly, using two wrenches.

4. Plug the two six-pin connectors together.

5. Slide the pipe coupling over the connectors.

6. Apply pipe-doping compound to the threads on the strain-relief body and screw it into the pipe coupling, while keeping the connectors inside the pipe coupling. Do not pull on the cable ends as this may loosen the connectors inside the coupling. Tighten firmly, using two wrenches .

7. On one side of the splice, slide the rubber bushing and cable grip up to the strain-relief body. Screw the knurled nut onto the strain-relief body until a small amount of resistance is felt.

8. Slide the splice assembly back and forth on the cable until the connectors are centered inside the coupling. 
9. While keeping the connectors centered in the coupling, tighten very firmly by hand the knurled nut onto the strain-relief body. Pliers may be used to ensure adequate tightening; however, overtightening will crack the plastic parts. Undertightening will allow the cable to slip out of the splice or allow the splice to leak.

10. Slide the second rubber bushing and cable grip up to the strain-relief body. Start screwing the knurled nut onto the strain-relief body and tighten very firmly by hand, as described in step 9 above.

11. Pull firmly on the cable, on each side of the splice, to test for proper cable gripping. If any cable slips out of the cable grip on the splice, the knurled nut is not tight enough or the cable is oily. In either case, the splice must be reassembled. A slippage problem may require that the cable, rubber bushings, and strain reliefs be cleaned with alcohol, to remove any oil or grease, before being reassembled.

\section{Changing the Battery-Pack Cable}

Refer to figures 5 and 7 during the procedure outlined below.

1. Remove the batteries from the battery holder by following steps 1 to 9 in the section "Installing or Changing Batteries."

2. Remove the knurled nut on the liquid-tight strain relief at the bottom of the battery-holder case.

3. Slide the knurled nut, cable grip, and rubber bushing several feet down the cable away from the strain-relief body.

4. Push the cable through the battery holder until the positive battery contact and the connector are exposed through the top of the battery holder.

5. Unplug the connector and set aside the battery spring, ribbon cable, and battery-contact assembly for later installation.

6. Unscrew the strain-relief body from the bottom of the battery holder. Pull the cable assembly out through the bottom of the battery holder. The cable has now been removed. The strain-relief body, rubber bushing, cable grip, and knurled nut are kept on the cable as they will not pass over the connector.

7. Check that the new battery-pack cable has the following parts at both ends: connector, strain-relief body, rubber bushing, cable grip, and knurled nut. Battery-pack cable fabrication is described in a previous section of this manual. Check the condition of the cable where the liquid-tight strain reliefs will grip. The cable must be free of oil and grease and must be smooth where the rubber bushing seals. The cable can be cleaned with alcohol. However, if the cable is rough, it must be cut and reterminated or replaced. 
8. At the end of the new battery-pack cable that is terminated with the female (sockets) connector, apply plastic-thread joint sealant to the threads of the strain-relief body and screw the strain-relief body into the bottom of the battery holder. Use a wrench to tighten firmly.

9. Run the cable with the connector up through the strain-relief body at the bottom of the battery holder and out the top of the battery holder.

10. Plug the cable connector into the connector on the positive battery contact, ribbon cable, and spring assembly.

11. Slide the positive battery contact back into the tube and pull it gently to the bottom of the tube using the cable. CAUTION: Pulling too hard will loosen the connector.

12. Slide the rubber bushing, cable grip, and knurled nut up the cable and into place at the strain-relief body. Screw the knurled nut onto the strain-relief body.

13. Pull gently on the cable to make sure the positive battery contact is resting on the bottom of the battery holder. Tighten the knurled nut very firmly by hand. Pliers may be used to ensure adequate tightening; however, overtightening will crack the plastic parts. Undertightening will allow the cable to slip out of the strain relief or the strain relief to leak. The battery contact may be pushed off the bottom of the battery holder when the knurled nut is tightened. This is normal and it will be pushed back down when the batteries are installed.

14. Pull on the cable firmly to test for proper cable gripping. If any cable slips out of the cable grip, then the knurled nut is not tight enough or the cable is oily. In either case, redo the connection.

15. Reinstall the batteries as described in the section of this manual titled "Installing or Changing Batteries."

\section{OPERATING THE R200}

After the $\mathrm{R} 200$ recorder is installed in a well, it must be set up to start recording data. The portable computer, called the data retriever, is used to set up the R200 and start the recording process. The R200 operator must use the data retriever to send several pieces of information to the R200 before the recording process can begin. This information includes:

- The correct time and date to set the clock in the recorder;

- the location of the well site (site identification);

- the name of the operator who is setting up the R200;

- the tape-down reading--the distance from the measuring point to the water (optional entry), and 
- the recorder position (the distance from the measuring point to the pressure port on the R200 probe).

An area of memory is set aside for the operator to enter general notes. The operator can enter information into this "notebook" area.

An operator may choose to enter things like "batteries changed on $\mathrm{mm} / \mathrm{dd} / \mathrm{yy}$ " or notes about any changes that might have occurred since his last visit to the site.

The user-entries and the data record are extracted from the R200 and placed in the data retriever in a file under a unique number.

When printing the record(s) or dumping into the Prime, the retriever allows the user to scroll through the data records and select the file(s) desired. These files are identified by file number, site identification, and the starting and ending times of the data record. After the file(s) have been processed, it can be erased to clear the data-record area of memory. Failure to clear the memory of outdated records may result in insufficient memory to accommodate data from all stations visited on a subsequent field trip. The data-storage memory in the data retriever is of the "fill-and-stop" type. When this memory is full of data, no more data files can be retrieved until some of the present data are processed and deleted.

In addition to the setup and data-retrieval functions of the R200, the data retriever can be used to read the time, the water level, and the battery voltage. These values can be read from the R200 at any time during the recording period without halting or interrupting the recording process.

\section{Connecting the Data Retriever}

An I200 serial-interface adapter is necessary to allow communications between the $\mathrm{R} 200$ recorder and the data retriever. This adapter converts the open-collector-type inputs and outputs of the R200 to the RS-232 used by the data retriever. Refer to figure 8 to connect the 200 to the data retriever in the following manner:

1. Remove the cap from the connector bottle at the top of the battery holder. Set the cap aside in a safe place.

2. Pull the connector out of the bottle and connect it to the mating connector on the I200. Check the alignment of the polarity keys before pushing the connectors together.

3. Connect the RS-232 connector on the I200 to the data-retriever's RS-232 port.

4. To operate as an R200 Retriever, the Tandy 102 computer must run the R200 Retriever program. This program consists of the following four BASIC program files: 


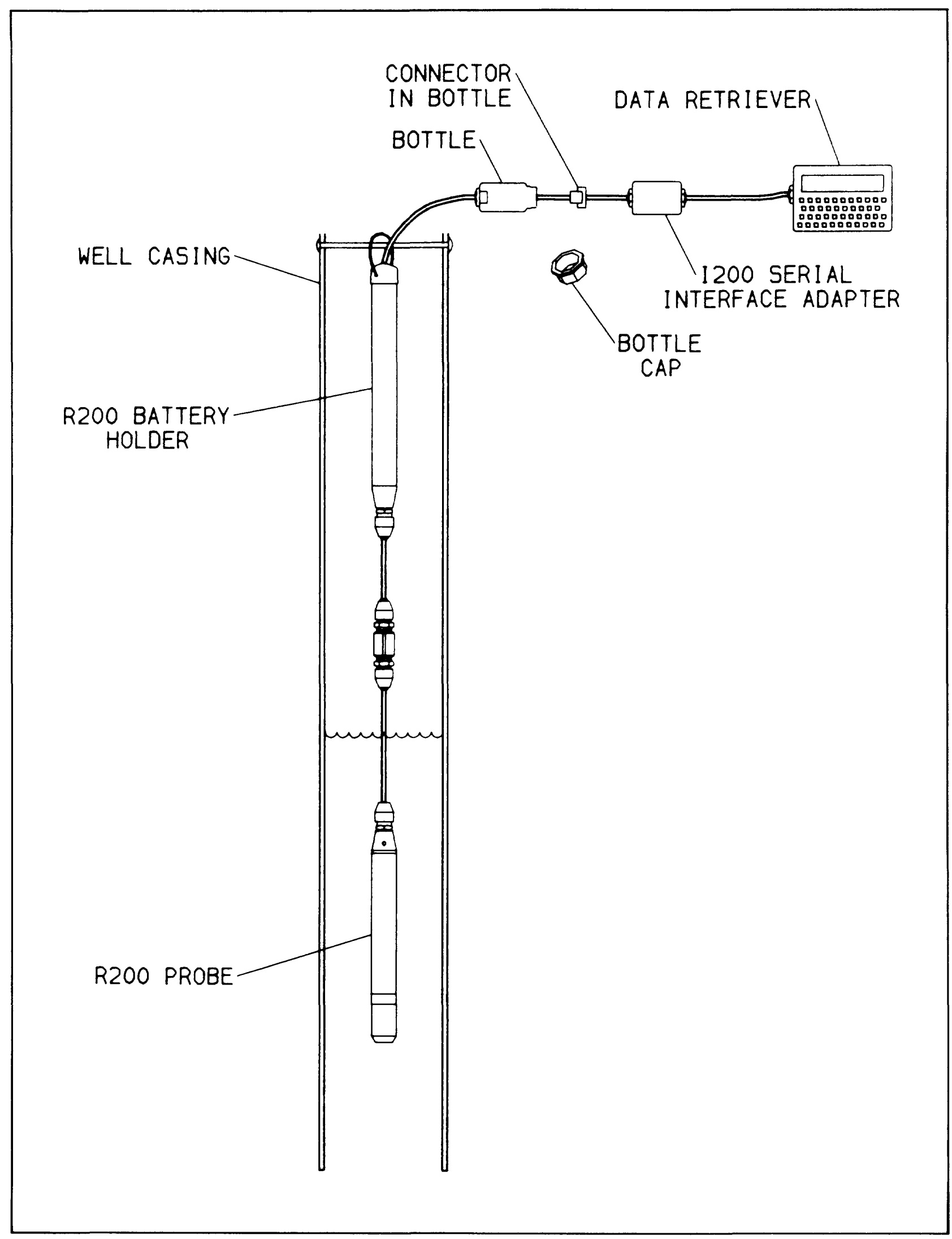

Figure 8.--Connection of the data retriever and R200. 
R200.BA (Power-on Initialization program)

R201.BA (Main Menu Selection program)

PRB.BA (Tandy 102 to R200 Communications program)

DAT.BA (Data-handling program)

Turn on the Tandy 102. The screen should display the TANDY operating system main menu.

5. Use the up-, down-, and left-arrow keys to place the cursor (highlight) over the filename "R200.BA." Press the ENTER key. If the R200 retriever program is intact and running properly, one of the screens described in the screen section of this manual will appear. Under normal operating procedures, screen 001 will appear first. The screen number is located in the lower right-hand corner of the screen. Follow the instructions on each screen as you work through the program.

If the file R200.BA does not reside in the Tandy or if screen 001 (time and data check) does not appear when you run program R200.BA, the program file is either not loaded or is not running correctly. To correct the problem, perform the following steps:

- Disconnect the R200 from the I200 adapter.

- Disconnect the I200 adapter from the Tandy 102.

- Turn off the Tandy 102 .

- Reconnect the Tandy 102 to the I200 adapter and the R200.

- Turn to the section in the manual entitled "Help with Specific Problems" and follow the directions under the heading "Retriever Program Not Running."

The following is an example of the sequence of events that occurs during normal operation of the Retriever with R200 system:

- The system is connected (Tandy to I200 to R200).

- The Tandy is turned on.

- The Tandy cursor is placed over R200.BA and "ENTER" is pressed.

- The label R200 RETRIEVER VERSION XXX appears briefly, followed by screen 001 (time and date check).

- $Y$ is pressed if time and date are correct. This causes screen 003 to appear.

- Operation is continued in this manner until the operations are completed and the user is instructed to turn the system off.

- Disconnect the R200 from the I200. Disconnect the I200 from the Tandy 102 .

- Turn off the Tandy 102 . 


\section{Running the Retriever Program}

The R200 data-retriever program is a menu-driven, user-friendly program written in the BASIC programming language. The user is asked to choose an operation and is then guided through the required procedures. Numerous screens will appear while running the retriever program. These screens tell the user what to do and ask various questions. Some of the questions require that the user enter text, while others are answered with a simple "Y" or "N" (yes or no). On some screens where the user must strike a key in response to a prompt, the key may need to be held down for a moment until the retriever program has accepted the answer. The screen will change when the keystroke is accepted. Some of the keystrokes must be followed by a carriage return (ENTER). On all of the screens, the abbreviation "CR" is used to denote the carriage return (ENTER) key.

Once the four BASIC files that make up the R200 retriever program have been loaded into the data retriever and saved in the memory expansion package (RAM "Booster Pak"), the R200 retriever program can be run at any time by running the R200.BA BASIC program.

\section{Calibration}

At several places in the R200 data-retriever program, the user is asked to select between two calibrations: A factory calibration and an in-well calibration. A11 R200's shipped from the HIF have been calibrated to improve the accuracy of their pressure measurements. This is called the factory calibration. Using factory calibration gives an accuracy of about 2 percent of the pressure-transducer range. If better accuracy is desired, then an in-well calibration can be performed on the R200 to improve the accuracy to about 0.5 percent of the pressure-transducer range. The in-well calibration procedure is done in the well at the time that the R200 is set up and started. This procedure is described in detail below.

Performing an in-well calibration on an R200 will greatly improve the accuracy of the water-level measurements made by the device. The in-well calibration procedure involves positioning the R200 probe at four known positions in the well, allowing the $\mathrm{R} 200$ to take readings at each of these positions, and entering the actual distance of the probe from the measuring point at each position. The retriever program guides the user through this calibration procedure on screens 141 through 164. 
Before performing an in-well calibration, the R200 user should first determine the distance from the measuring point (usually the top of the well casing) to the water surface and then record this value. After making the measurement, the user begins the in-well calibration procedure in the retriever program by selecting item 1 (IN-WELL CALIBRATION) on screen 140. The procedures involved in the calibration are listed below:

1. Screen 141 of the retriever program will appear after the user selects "IN-WELL CALIBRATION" on screen 140. Screen 141 instructs the user to raise the probe out of the water. When installing a new $R 200$, the user should first lower the R200 into the well far enough to submerge the probe section. This ensures that the pressure port on the probe is filled with water as required for the calibration procedure. The probe then should be raised above the water surface and held there. The exact position of the probe is not important here as long as the probe is above the water surface and the pressure port is filled with water. Readings will be displayed on the retriever screen. When these readings become stable, press and hold CR (ENTER) until screen 142 appears.

2. Screen 142 is used to ensure that the value accepted for the out-ofwater reading is typical of the values that were being displayed on screen 141. The user enters $Y$ (yes) if the displayed value is typical, or $N$ if it is not. If $N$ (no) is entered, screen 141 will reappear and allow the out-of-water reading to be retaken.

3. The user is next instructed, on screen 143, to lower the probe into the water to some known position where the readings being displayed on the retriever are near 10 percent. The 10 -percent readings should occur at a point where the pressure port on the probe is submerged by an amount approximately equal to 10 percent of the transducer range. The user should lower the probe until the displayed reading is near 10 percent. (Anything between 5 percent and 20 percent will suffice.) Once the 10 -percent calibration point is reached, the probe should be held stationary, and the user should make a note of the actual distance from the measuring point at the top of the well to the pressure port on the R200 probe. The probe must be held at this position until the readings stabilize. The user should then press and hold CR (ENTER) until screen 144 appears.

NOTE: During the in-well calibration procedure, it may be desirable to use a support line for raising and lowering the probe to the required positions. This calibration method is depicted in figure 9 for the 10 -percent calibration point.

4. Screen 144 appears next and allows the user to verify that the reading accepted for the 10-percent calibration point was typical of the displayed values. The user enters $\mathrm{Y}$ if the displayed value is typical or $\mathrm{N}$ if it is not. If $N$ is entered, screen 143 will reappear and allow the 10 -percent reading to be retaken. 


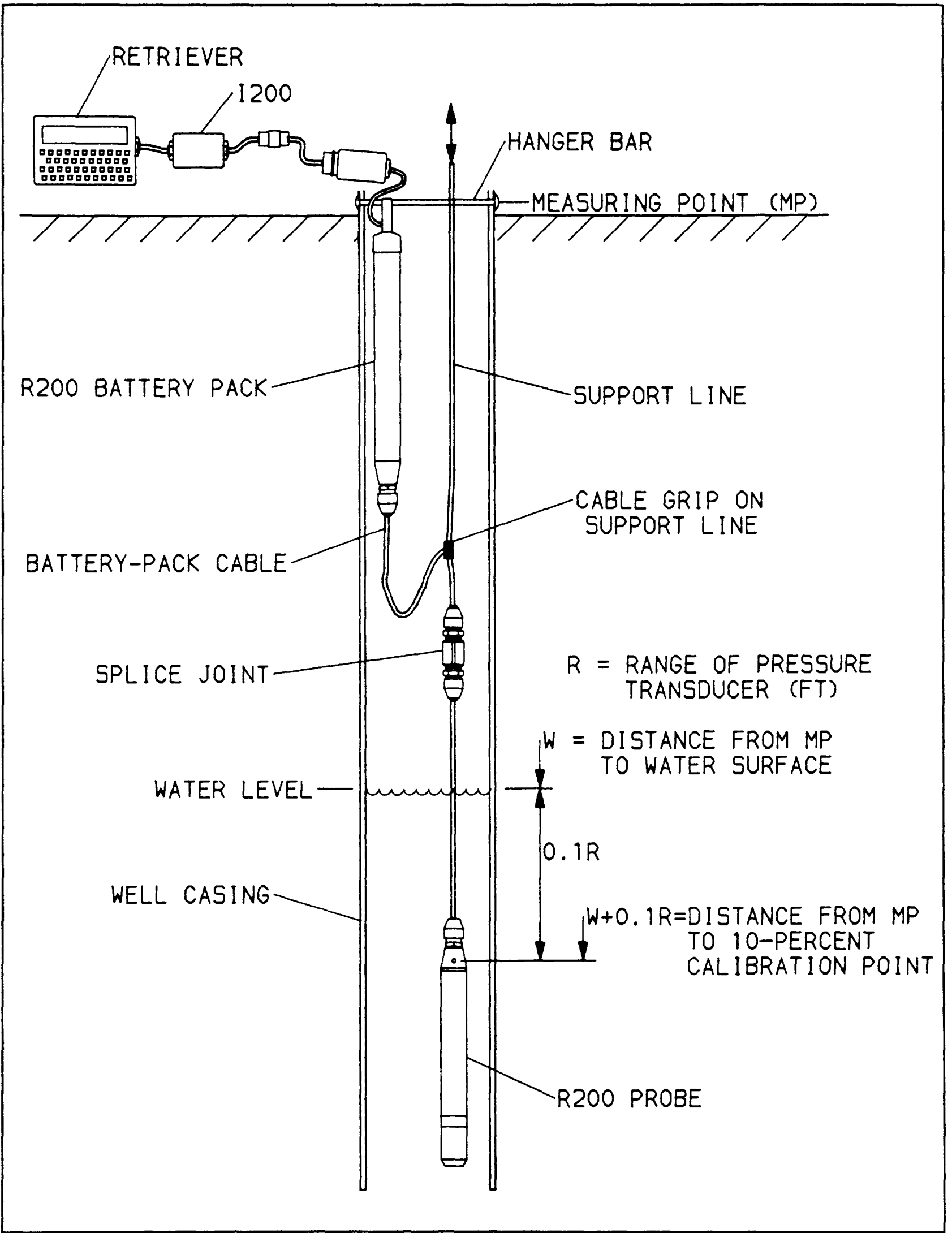

Figure 9.--Use of support line for in-well calibration at the 10-percent calibration point. 
5. The user is next asked, on screen 145, to enter the distance from the measuring point to the probe. This is the distance from the measuring point at the top of the well to the pressure port on the R200 probe. The distance is entered, in feet, with two digits following the decimal point for hundredths of a foot. This entry is terminated with a CR (ENTER), which causes screen 146 to appear.

HINT: If a support line is to be used during calibration and will remain in the well to suspend the R200 during the next recording period, it may be desirable to place markings on the support line at each of the calibration points for future reference. As long as the support line remains attached to the battery-pack cable at the same point, the distances from each marking on the support line to the pressure port on the probe will remain constant. The distances from each marking to the pressure port can then be recorded and used for distance measurements during future calibrations.

6. Screen 146 instructs the user to lower the probe to a known position where the displayed readings are near 50 percent. The 50 -percent readings should occur at a point where the pressure port on the probe is submerged by an amount approximately equal to 50 percent of the transducer range.

NOTE: In a shallow we11, where the distance from the water surface to the bottom of the well is less than the range of the pressure transducer, place the probe halfway between the water surface and the bottom of the well for this part of the calibration. Doing this will cause the displayed readings to be less than 50 percent, but this does not matter as 1 ong as the actual distance from the measuring point to the probe is entered later on screen 145 .

NOTE: If the combined length of the probe cable and the battery-pack cable is too short to allow the probe to be lowered to the 50-percent calibration point, then a calibration cable will be needed along with some method of lowering the entire R200 (probe and battery pack) into the well. Figure 10 depicts this situation for the 90 -percent calibration point. This figure suggests using a support line in an "inverted" manner to lower the R200. A calibration cable is used to extend the I/O connector to the top of the well to allow retriever communications. CAUTION: When using the calibration cable, some form of support line must be used to suspend the $R 200$ as the calibration cable cannot support the weight of an $R 200$. At its unused end, this support line should be fastened to something sturdy to prevent loss of the entire R200 unit if the support line is released.

The user should lower the probe until the displayed readings are near 50 percent. (Anything between 40 and 60 percent will suffice.) Once the 50 -percent calibration point is reached, the probe should be held stationary and the user should make a note of the actual distance from the measuring point at the top of the well to the pressure port on the probe. The probe must be held at this position until the readings being displayed on the retriever become stable. The user should then press and hold CR (ENTER) until screen 147 appears. 


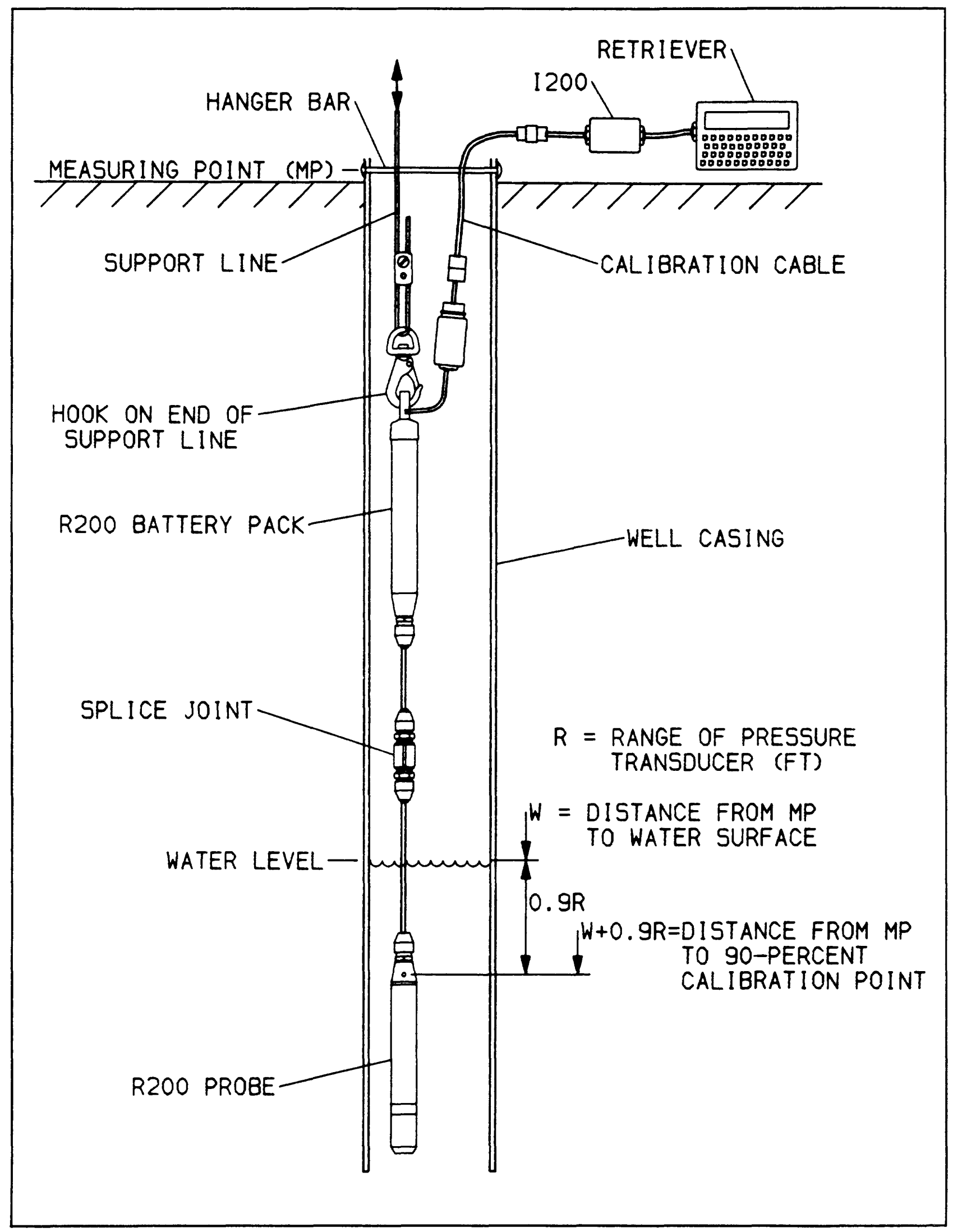

Figure 10.--Achievement of 90-percent calibration-point depth using calibration cable and support line. 
7. Screen 147 appears next and allows the user to verify that the reading accepted for the 50-percent calibration point was typical of the displayed values. The user enters $Y$ if the displayed value is typical, or $N$ if it is not. If $N$ (no) is entered, screen 146 will reappear and allow the 50 -percent reading to be retaken.

8. Screen 145 now appears once again. The user is asked to enter the dis tance from the measuring point to the probe. The distance is entered in feet with two digits following the decimal point for hundredths of a foot. The user ends the entry with CR (ENTER).

9. Screen 148 now appears on the retriever and instructs the user to lower the probe to a known position where the displayed readings are near 90 percent. The 90 -percent reading should occur at a point where the pressure port on the probe is submerged by an amount approximately equal to 90 percent of the transducer range.

NOTE: In shallow wells where the distance from the water surface to the bottom of the well is less than the range of the pressure transducer, place the probe at the bottom of the well for this part of the calibration. Doing this may cause the displayed readings to be less than 90 percent, but this does not matter as long as the actual distance from the measuring point to the probe is entered later on screen 145.

NOTE: If the combined length of the probe cable and the battery-pack cable is too short to allow the probe to be lowered to the 90 -percent calibration point, a calibration cable will be needed along with some method of lowering the entire R200 (probe and battery pack) into the we11. Figure 10 depicts this situation for the 90 -percent calibration point. This figure suggests using a support line in an "inverted" manner to lower the R200. The calibration cable is used to extend the $I / 0$ connector to the top of the we11 to allow retriever communications. CAUTION: When using the calibration cable, sone form of support line must be used to suspend the R200 as the calibration cable cannot support the weight of an R200. At its unused end, this support line should be fastened to something sturdy to prevent loss of the entire R200 unit if the support line is released.

The user should lower the probe until the displayed readings are near 90 percent. (Anything between 80 and 100 percent will suffice.) Once the 90 -percent calibration point is reached, the probe should be held stationary and the user should make a note of the actual distance from the measuring point at the top of the well to the pressure port on the probe. The probe must be held at this position until the readings being displayed on the retriever become stable. The user should then press and hold CR (ENTER) until screen 149 appears.

10. Screen 149 appears next and allows the user to verify that the reading accepted for the 90 -percent calibration point was typical of the displayed values. The user enters $Y$ if the displayed value is typical, or $N$ if it is not. If $N$ is entered, screen 148 will reappear and allow the 90 -percent reading to be retaken. 
11. Screen 145 reappears. The user is asked to enter the distance from the measuring point to the probe. The distance is entered, in feet, with two digits following the decimal point for hundredths of a foot. The user ends the entry with CR (ENTER).

12. Screen 160 appears on the retriever. This screen instructs the user to anchor the probe in the recording position where it will remain for the next recording period. The recording position should have been calculated previously using the worksheet and accompanying figure. (Copies of the worksheet appear in a previous section of the manual.) If the expected minimum and maximum water levels entered on the worksheet are still valid for the well, the recording position calculated on the worksheet should be satisfactory. However, if the water level has, for example, dropped very near or below the expected minimum for the well, the user may wish to anchor the probe at a slightly deeper position in the well to account for the decline of the water table. At any rate, after the probe is anchored in its recording position, the user enters the distance from the measuring point to the pressure port on the probe, in feet, followed by CR (ENTER).

13. Screen 161 appears next and allows the user to verify that the proper recording position was entered on screen 160 .

14. After entering the recording position on screen 160 and verifying the entry on screen 161 , screen 162 appears. This screen allows the user to enter a tape-down reading if desired. The tape-down reading is the distance from the measuring point to the water surface. This value is not used in the data record in any way and can be omitted if desired by entering $N$.

15. Screen 163 simply allows the user to verify that the proper tape-down reading was entered on screen 162 .

16. Screen 164 appears next and displays the present water level, using the calibration just completed or using the factory calibration if selected. The "FT TO WATER" displayed is the distance from the measuring point to the water surface. The "PRESSURE FT" displayed is the amount of water over the probe. The tape-down reading entered previously is also displayed. The sum of the "FT TO WATER" and the "PRESSURE FT" should be equal to the distance from the probe to the measuring point (entered on screen 160). If everything on this screen seems valid, then pressing $Y$ will end the calibration procedure. If something is in error, pressing $N$ will cause the entire calibration procedure to be repeated. 


\section{SCREENS}

The pages in this section contain descriptions of each screen that appears on the data retriever while the $\mathrm{R} 200$ retriever program is running. Each screen that appears in the retriever program has a screen number located in the bottom right-hand corner. This screen number can be used to locate a detailed explanation of the screen in this manual. For each screen number, an illustration of the screen is shown along with a detailed explanation of the screen and the choices that the user must make. This section of the manual contains a listing of all screens in numerical order. The screens may not appear in the order listed in this manual because the screen order depends upon the choices made by the user. Some gaps have been left in the screen numbers. Screen numbers have been assigned in the following general format:

$\begin{array}{ll}000 \text { to } 099 & \text { Main menu and common screens } \\ 100 \text { to } 199 & \text { Functions performed with probe attached } \\ 200 \text { to } 299 & \text { Reviewing data on screen } \\ 300 \text { to } 399 & \text { Printing of data on external printer } \\ 400 \text { to } 499 & \text { Sending files to another computer } \\ 600 \text { to } 699 & \text { Erasing files } \\ \text { E01 to E99 } & \text { Screens for various error conditions }\end{array}$


RET MO-DY-YR HR:MN : SC

TIME NN-NN-NNNN NN:NN:NN

IS TIME OK? $\mathrm{Y} / \mathrm{N}$

This screen appears when the retriever program is started initially and displays the date and time present in the retriever. If the time is correct, the user presses $Y$ and the main menu (screen 003) will appear. If the time is not correct, pressing $N$ will take the user to screen 002 , which is used to set the time. 


\begin{tabular}{|l|}
\hline ENTER TIME USING 10 \\
DIGITS (24HR CLK) \\
CR STARTS CLOCK \\
MODYYRHRMN(CR) \\
$>$ \\
\end{tabular}

This screen is requesting that the date and time be entered. The prompt MODYYRHRMN(CR) is asking the user to enter 2 digits each for the month, day, year, hour, and minute. These entries appear directly beneath their respective prompts on the screen as they are typed. Note that the hour must be entered for a 24-hour clock. The final entry is the CR (carriage return or enter), which will set the retriever clock to the time entered. The seconds will always be set to 00 when $C R$ is pressed. It is very important to set the retriever clock correctly. 


\begin{tabular}{|lll|}
\hline 1 & PROBE FUNCTIONS \\
2 & DISPLAY DATA FILE \\
3 & PRINT DATA FILE & \\
4 & DUMP MAIN FILES TO PRIME & \\
5 & DUMP BACKUP FILES TO PRIME & \\
6 & ERASE SELECTED FILE & \\
7 & QUIT & 003 \\
& SELECT $1-7$ & 00 \\
\hline
\end{tabular}

This is the main menu from which the user chooses any one of seven retriever functions by entering a number from 1 to 7 . Possible functions follow:

1. PROBE FUNCTIONS--Use to perform any operation concerning the R200 probe, such as reading the water level, battery voltage, or probe time; or retrieving the data and starting a new record. If this is a new installation of an R200, the user must make this selection first to set up the new recorder. After this selection is made, the probe function menu (screen 100) will appear.

2. DISPLAY DATA FILE--Use to display any data file contained in the retriever on the retriever screen. After making this selection, screen 200 appears, allowing selection of the file to display.

3. PRINT DATA FILE--Use to print any data file contained in the retriever on an externally connected printer. After making this selection, screen 300 appears, allowing selection of the printer type.

4. DUMP MAIN FILES TO PRIME--Use to initially dump the data files to the Prime computer. When this is done, all backup files residing in the retriever are deleted, and the main data files become backup data files. After making this selection, screen 400 appears to verify the erasure of the backups.

The main data files are dumped to the Prime in the R200 raw data format. To dump the R200 data in another format, the main data files must first be dumped in R200 raw data format using this selection (4). This action causes the main files to be renamed as backup files. The user can then dump these backup files to the Prime in any one of three formats by selecting item 5 on this screen.

(This screen explanation continues on the next page.) 
5. DUMP BACKUP FILES TO PRIME--The backup data files are sent to the Prime computer in any one of three selectable data formats. All main data files residing in the retriever must first be dumped to the Prime, using item 4 on this screen. Once this is done, the user can then dump the backup files to the Prime in any one of three formats: R200 raw data format, WRD standard data format, or Daily-Value Card-Image format. Screen 405 will appear next and allows the user to select the data format to be used for dumping the backup data to the Prime.

6. ERASE SELECTED FILE--Use to erase a certain data file. The file description screen (200) appears, and the user selects the desired file to erase. Erasure of a file may be desirable if it contains no useful data. CAUTION: Be careful not to erase any useful data because it cannot be recovered after being erased.

7. QUIT--The retriever goes to the program beginning and turns off. When the power switch is pressed, the retriever will start from the program beginning. Using the power switch to exit the retriever program is not recommended, because, when the retriever is turned on once again, the program will not start from the beginning. 


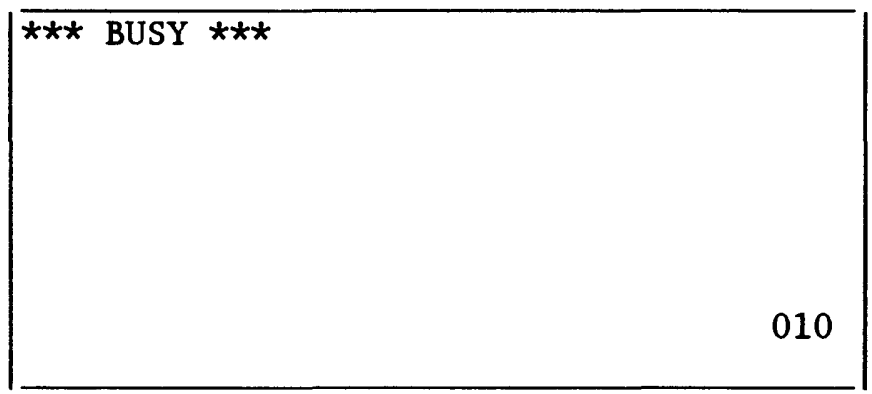

The retriever is busy doing a job that was requested. This often involves a job where a large amount of data, such as the header information entered by the operator, is passed to or from the R200. Be patient; the retriever will finish and the next screen will appear automatically. 


\begin{tabular}{|lll|}
\hline 1 & DISPLAY TIME \\
2 & CURRENT READING & \\
3 & RETRIEVE DATA & \\
4 & QUIT PROBE FUNCTIONS & \\
$1,2,3$ OR $4 ?$ & 100 \\
& & \\
\hline
\end{tabular}

This is the main probe menu. The user presses a number from 1 to 4, selecting one of the following instructions:

1. DISPLAY TIME--The retriever and the R200 dates and times are displayed (screen 110).

2. CURRENT READING--The present pressure and water-leve1 readings will be displayed. This will be followed by a screen showing the R200 battery voltage. Screen 120 follows this selection, asking the user to select the calibration method to use for the displayed data.

3. RETRIEVE DATA--The data-retrieval process is entered. If the user is performing an installation of a new R200 or an installation of an R200 at a new site, this selection must be made to allow a new record to be started. If this is the case, the collection of the data can be skipped later in the process (on screen 170). Once the data-retrieval process is started, it must be completed. It is quite long and involves screens 130 through 178. During this process, the user enters header values, calibrates the probe, collects data, and starts the recorder for the next recording period. Following this selection, screen 130 will appear, asking the user to verify the start of the retrieval process.

4. QUIT PROBE FUNCTIONS--The R200 is put into its low-power state. The user then is asked to disconnect the $\mathrm{R} 200$ (screen 180) and a return is made to the main menu (screen 003). 


\begin{tabular}{|llll|}
\hline TIME & MO-DY - YR & HR:MN :SC \\
PROBE & NN-NN-NN & NN:NN:NN & \\
RET & NN-NN-19NN & NN:NN:NN & \\
CR- $>$ PROBE MENU & & \\
& & & 110 \\
& & & \\
\hline
\end{tabular}

This screen shows the present retriever and R200 date and time. The R200 clock only updates every 7.5 seconds. Thus, the retriever time is seen to change more often than the R200 time. The software also causes the screen to display less often than once a second. This results in the retriever time often incrementing by 2 seconds. Press and hold CR (ENTER) to return to the probe menu (screen 100). 


\begin{tabular}{|lll|}
\hline 1 & DISPLAY USING FACTORY CAL & \\
2 & DISPLAY USING IN-WELL CAL & \\
3 GO BACK TO PROBE MENU & \\
1,2 OR $3 ?$ & & 120 \\
\hline
\end{tabular}

This screen appears before the displaying of data and asks the user to choose the type of calibration desired. All the data are stored in an uncalibrated form in the R200. The retriever takes this data and applies calibration equations to it, using either a standard set of calibration coefficients (factory cal) or a custom set of coefficients found when the probe was last calibrated in the well (in-well cal). Select the type desired by pressing 1,2 or 3 for the functions as follows:

1. DISPIAY USING FACTORY CAL--The coefficients representing the nominal probe are used to calculate the feet of water above the probe. This value is shown on screen 121. Using factory calibration will give an accuracy of 2 percent.

2. DISPLAY USING IN-WELL CAL--The calibration coefficients and the recorder position found during the latest in-well probe calibration are used to display the feet of water above the probe and the distance from the measuring point to the water surface. These appear in screen 122 . In-well calibration will give an accuracy of 0.5 percent. If the probe batteries were changed after the calibration or if the probe is newly installed, the distances displayed will be in error because the in-well calibration coefficients are not yet present in the probe. This will normally cause the distances to read zero.

3. GO BACK TO PROBE MENU--A return is made to the probe menu (screen 100). 


$$
\begin{aligned}
& \text { FACTORY CAL } \\
& \text { PRESSURE=NNN.NN FT * } \\
& \text { CR-->BATTERY VOLT }
\end{aligned}
$$

The current pressure reading, in feet, is displayed. Factory calibration is assumed, and coefficients for the calibration equations are set to the nominal values for an average probe, giving an accuracy of 2 percent of full scale. The asterisk (*) on the screen will blink each time the screen receives a new reading from the R200 probe. Note that when the probe pressure is read for the first time, a 10 -second delay will occur before the reading appears. This is caused by the probe transducer needing to warm up after power-on. After the warmup period, the reading will update about once every second.

The screen is ended by holding the CR (ENTER) key down. This will cause the battery-voltage screen (123) to appear. 


$\mid$\begin{tabular}{ll|}
\hline PRESSURE FT= NNN.NN * & \\
FT TO WATER-NNNN.NN & \\
CR-->BAT VOLT & 122 \\
\end{tabular}

The distance, in feet, of water above the transducer (PRESSURE FT) and the distance, in feet, from the measuring point to the water surface (FT TO WATER) are displayed. The display is updated each time the asterisk blinks. When this function is called for the first time, a 10-second delay will occur before the first reading appears. This gives the transducer time to warm up and stabilize. The values displayed are calculated using the calibration coefficients found during the last in-well probe calibration.

This screen is ended by pressing and holding the CR (ENTER) key. This will cause the battery-voltage screen (123) to appear. 


\begin{tabular}{|l} 
R200 BATTERY N.NN VOLTS * \\
CR-->PROBE MENU \\
\\
\end{tabular}

The R200 battery voltage is displayed. The asterisk (*) blinks each time the display updates. The voltage is measured at the probe and may be lower than the actual battery voltage due to losses in the cable. This loss will be about 0.03 volts for each 100 feet of 22 -gage cable, but will vary with the cable type. Use the guide below to determine if battery replacement is necessary.

\begin{tabular}{|c|c|c|}
\hline \multicolumn{3}{|c|}{ Battery } \\
\hline Battery & life left & Days of \\
\hline voltage & (percent) & recording left \\
\hline 9.3 & 100 & 400 \\
\hline 9 & 90 & 400 \\
\hline 8.4 & 50 & 400 \\
\hline 8.1 & 30 & 250 \\
\hline 7.8 & 10 & 100 \\
\hline
\end{tabular}

Batteries should be replaced any time they are below 8.4 volts. The batteries can be measured at the surface, bypassing any cable loss, by connecting a voltmeter from pin 3 (positive) to pin 4 (negative) on the battery-holder I/O connector (bottle connector). The R200 should function with the battery voltage down to 6.5 volts, allowing the user to retrieve the data even when the batteries are extremely low.

This screen is ended by pressing and holding the CR (ENTER) key. This will cause the probe menu (screen 100) to appear. 


\begin{tabular}{|l|}
\hline ARE YOU SURE YOU \\
WANT TO STOP RECORDER AND \\
RETRIEVE DATA? \\
Y/N? \\
\\
\end{tabular}

This screen is waiting for confirmation of a previous request to enter the data-retrieval mode. Once this mode is entered, it cannot be stopped. Answering $Y$ (yes) causes screen 131 to appear and the following events to occur:

1. The present recording process is stopped.

2. Header items are entered by the user (site identification, operator name, ending notes, and so forth).

3. The user performs a calibration.

4. The data are retrieved unless the user skips over the retrieval process (screen 170).

5. The recorder is started for the next data-recording period.

If the user does not want to perform the data retrieval, press $N$ (no) to cause the main menu (screen 003) to appear.

NOTE: If this is a new installation of an R200 or if the R200 batteries have just been changed, the user should enter $Y$. 


$$
\text { OPERATOR NAME= }
$$

AAAAAAAAAA

OK Y/N?

This screen displays the operator name that is in the R200 header. If the present operator is the same, $Y$ should be entered to leave the name unchanged. Proceed to screen 133. If the present operator is different, $N$ should be entered. Enter a new operator name on screen 132. The operator name is limited to 10 letters. The name that appears on this screen the first time will be the beginning operator name in the header (the operator who started the recording cycle). The ending operator name in the header of the collected data will be the same name if not changed ( $Y$ entered) but will be a new name if changed ( $N$ entered). 


\section{ENTER OPERATOR NAME}

$* * * * * * * * * *(\mathrm{CR})$

$>$

The user is to enter a new operator name. The asterisks indicate the maximum length of 10 characters. The name is terminated with a CR (ENTER). Note that the left-arrow key $(+)$ can be used to correct typing errors. Screen 133 is the next screen to be displayed. 
SITE ID=

AAAAAAAAAAAAAAA

OK $\mathrm{Y} / \mathrm{N}$ ?

This screen is displaying the site identification. If it is correct, the user enters $Y$ and proceeds to screen 135. If it is incorrect, the user enters $\mathrm{N}$ to allow it to be changed on screen 134. The only time the site identification should need changing is if the R200 batteries have been removed or the $\mathrm{R} 200$ was moved to a different site. The final site identification appears in the header of the collected data record. 


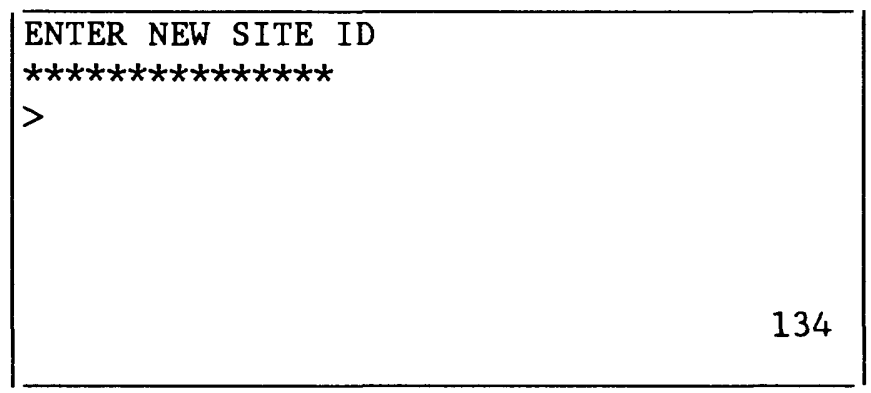

A new site identification is to be entered. The asterisks indicate that this identification can be up to 15 characters long. The site identification can be less than 15 characters and is terminated by CR (ENTER). The site identification entered will appear in the header of the collected data record. The left-arrow key $(+)$ can be used to correct any typing errors. Screen 135 is the next screen to be displayed. 


\begin{tabular}{|l|}
\hline LATITUDE LONGITUDE \\
DDMMS SDDDMMSS \\
NNNNNNNNNNNN \\
OK Y/N? \\
\\
\end{tabular}

The latitude and longitude of the site location in the R200 header is shown. The letters above the numbers indicate which numbers are degrees (D), minutes (M), and seconds (S). If the screen shows the correct latitude and longitude, the user enters $Y$ and proceeds to screen 137. If the latitude or longitude is wrong, the user enters $N$ and is allowed to enter a new latitude and longitude on screen 136. Normally this value should be correct, unless the $\mathrm{R} 200$ was moved to a different we11 or the batteries were removed. The final latitude and longitude accepted will appear in the header of the collected data record. 


\begin{tabular}{|l|}
\hline LATITUDE LONGITUDE \\
DDMMSSDDDMMSS \\
$>$ \\
INPUT NEW LAT \& LONG \\
\\
\end{tabular}

The user is to enter 13 numerical digits for the latitude and the longitude. The letters above the cursor indicate whether the user is entering degrees (D), minutes (M), or seconds (S). Only numbers are allowed. The left-arrow key $(\leftarrow)$ can be used to correct typing errors. A CR (ENTER) ends the entry. Screen 137 is the next screen to be displayed. 


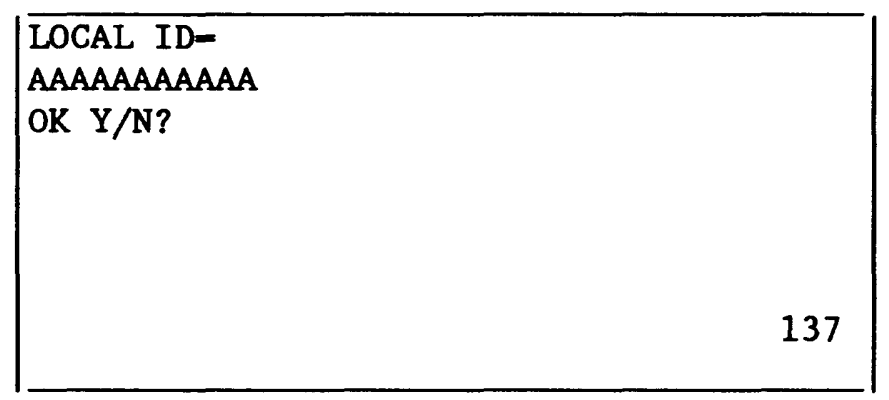

The local identification present in the $\mathrm{R} 200$ header is displayed. If it is correct, the user enters $Y$ and proceeds to screen 139 . If it is incorrect, the user enters $\mathrm{N}$, and is then allowed to change the local identification on screen 138. The local identification can be up to 11 characters 1ong. This screen usually will be correct unless the batteries have been removed or the $\mathrm{R} 200$ has been moved to a new site. The local identification will appear in the header of the collected data record. 


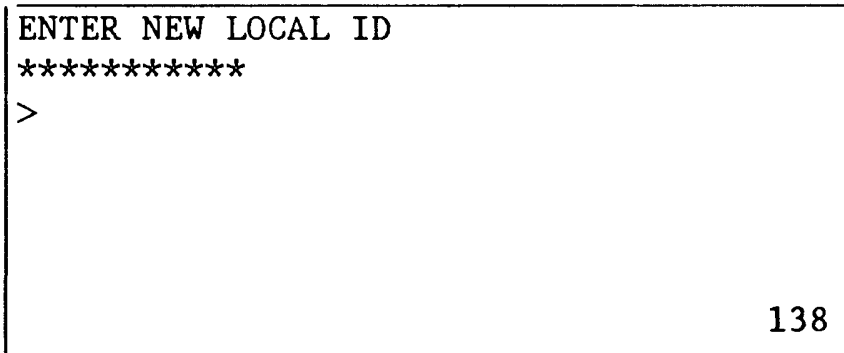

The user enters a new local identification. The asterisks above the prompt indicate that up to 11 alphanumeric characters can be entered. The left-arrow key $(\leftarrow)$ can be used to correct typing errors in the entry. The entry ends with a CR (ENTER). This entry goes into the header area in the data record. Screen 139 is the next screen to be displayed. 


\begin{tabular}{|l|}
\hline IS ALL OK? Y/N? \\
\\
\end{tabular}

Is information entered in the previous screens correct? If everything is all right, enter $Y$ and proceed to screen 140 . If a mistake was made in a previous screen, enter $N$. This will cause a repeat of screen 130, allowing the station identification information to be entered again. 


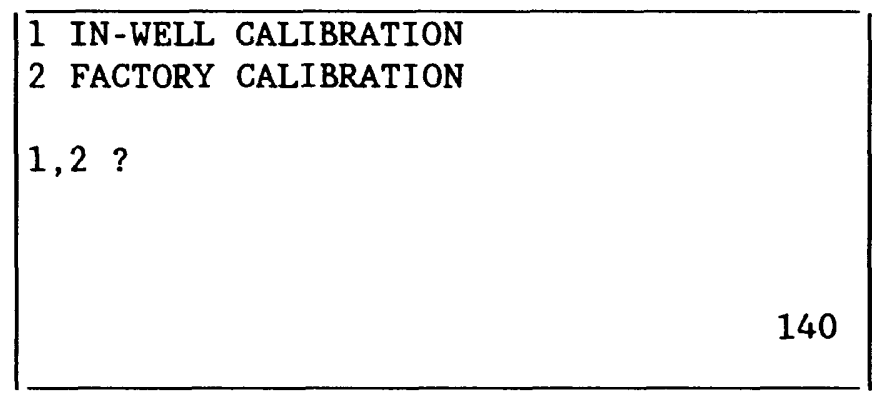

The user presses 1 or 2 as described below to choose the type of calibration desired.

1. IN-WELL CALIBRATION--This method provides the user with the greatest accuracy. The user will be requested, in screens 141 to 149 , to position the R200 probe at four places in the well and enter the distance to the probe. The four positions are

- one out of the water, and

- three in the water at depths corresponding to 10 percent, 50 percent, and 90 percent of the transducer full-scale range.

This calibration method gives an accuracy of 0.5 percent of full scale. The in-well calibration procedure is described in detail in the section of the manual called "calibration," and a brief explanation accompanies each of the screen definitions for screens 141 to 149.

2. FACTORY CALIBRATION--This method sacrifices accuracy to simplify R200 operation. The calibration steps of raising and lowering the probe to four different positions are bypassed, and the next screen displayed is screen 160. Default values for the probe span and zero coefficients are inserted into the R200 header. The accuracy obtained depends on how much the probe has drifted since it was calibrated at the time of assembly. Transducer specifications indicate a maximum drift of about 0.5 percent of full scale for each year. Other factors affecting the accuracy of this method are

- the change in water density due to dissolved or suspended materials in the water, and

- temperature drift of the probe as it is at a different temperature than when it was calibrated.

The probes are calibrated at room temperature (about $25{ }^{\circ} \mathrm{C}$ ) and may drift about 1 percent for a $25^{\circ}$ change. With all these factors, only an accuracy of 2 percent of full scale is specified even though 1 percent or better may be attained in ideal conditions. 


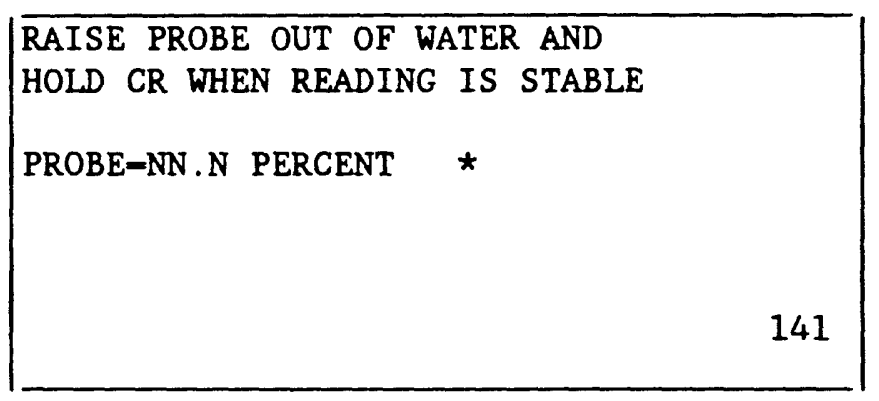

Pu1l the R200 probe out of the water. Wait for the reading to stabilize and then hold down CR (ENTER) until screen 142 appears. The first reading may not appear for 10 seconds because the probe requires a warmup period. The asterisk will blink each time the display updates. This reading is taken to determine the probe offset and is used to help determine the zero coefficients ( $\mathrm{Zl}$ and $\mathrm{Z2}$ ) in the header that accompanies the data file.

NOTE: Do not empty the water out of the transducer port on the probe. The transducer port should remain filled with water during this calibration step. 


\begin{tabular}{l}
\hline RAISE PROBE OUT OF WATER AND \\
HOLD CR WHEN READING IS STABLE \\
PROBE-NN.N PERCENT * \\
IS THIS VALUE OK? Y/N?
\end{tabular}

If the value on the screen was the most frequently displayed reading with the probe out of the water, press $Y$ and proceed to screen 143. This will cause this reading to be the one used in determining the calibration coefficients in the header. If the reading on the screen is not typical of the out-of-water readings, press $N$. This will allow reading of the probe again (repeat screen 141). 


\begin{tabular}{|l}
\hline MOVE PROBE TO A KNOWN POSITION \\
GIVING A READING NEAR 108 \\
HOLD CR WHEN STABLE \\
PROBE=NN.N PERCENT * \\
\end{tabular}

The user lowers the probe into the water to a known depth of about 10 percent of the transducer range. The display above indicates the percent depth. A reading may not be displayed for 10 seconds because the probe needs a warmup time. The asterisk blinks each time the display updates. The distance need not be exactly 10 percent, but can range from 5 to 20 percent. When the reading on the screen appears stable, make a note of the distance from the measuring point to the pressure port on the probe and hold CR down until screen 144 appears. After screen 144 appears, the probe can be moved. 
MOVE PROBE TO A KNOWN POSITION

GIVING A READING NEAR 10\%

HOLD CR WHEN STABLE

PROBE- NN.N PERCENT *

IS THIS VALUE OK Y/N?

The value read from the probe will be used for the low-range calibration point and appears on the screen above. If it was the most frequently occurring reading from the previous screen, press $Y$ to accept it and proceed to screen 145 . If it does not represent the typical value read on screen 143 , press $N$ to allow a retry of screen 143 . 


\begin{tabular}{ll}
\hline ENTER DISTANCE FROM MEASURING POINT \\
TO PROBE \\
$\star * \star * . * *$ FT & \\
$>$ & \\
& 145 \\
\hline
\end{tabular}

The user is to enter the distance, in feet, from the measuring point at the top of the well to the pressure port on the probe. This entry must be the exact distance at which the probe was positioned when the previous calibration screen $(143,146$, or 148) was ended. The asterisks above the cursor indicate 4 digits to be entered for feet, a decimal point, and then 2 digits for hundredths of a foot. The left-arrow key $(+)$ can be used to correct invalid entries. Press CR (ENTER) to end the screen.

CAUTION: If the probe distance is not entered correctly, the probe will not be calibrated properly. 


\begin{tabular}{|l|l|}
\hline MOVE PROBE TO A KNOWN POSITION \\
GIVING A READING NEAR 50\% \\
HOLD CR WHEN STABLE & \\
PROBE=NN.N PERCENT * & \\
& \\
\end{tabular}

The user lowers the probe to a known depth of about 50 percent of the transducer range. The display above indicates the percent depth. A reading may not be displayed for 10 seconds because the probe needs a warmup time. The asterisk blinks each time the display updates. The distance need not be at exactly 50 percent but can range from 40 to 60 percent. (See exception below.) When the reading on the screen appears stable, make a note of the distance from the measuring point to the pressure port on the probe and hold CR (ENTER) down until screen 147 appears. After screen 147 appears, the probe can be moved.

NOTE: If the distance from the water surface to the bottom of the well is less than the range of the transducer, place the probe halfway between the water surface and the bottom of the well instead of at the 50-percent depth. This is necessary because the probe cannot be submerged to the 90 -percent depth shown in screen 148 . This will cause the displayed readings to be less than 50 percent. 
MOVE PROBE TO A KNOWN POSITION

GIVING A READING NEAR 50 \%

HOLD CR WHEN STABLE

PROBE- NN.N PERCENT *

IS THIS VALUE OK $\mathrm{Y} / \mathrm{N}$ ?

The value read from the probe that will be used for the midrange calibration point appears on the screen above. If it was the most frequently occurring reading from the previous screen, press $Y$ to accept it and proceed to screen 145 . If it does not represent the typical value read on screen 146 , press $\mathrm{N}$ to allow a retry of screen 146 . 


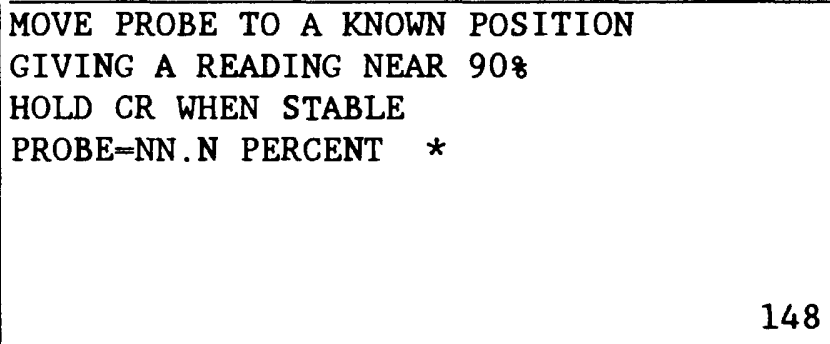

The user lowers the probe to a known depth of about 90 percent of the transducer range. The display above indicates the percent depth. A reading may not be displayed for 10 seconds because the probe needs a warmup time. The asterisk blinks each time the display is updated. The distance need not be at exactly 90 percent but can range from 80 to 100 percent. (See exception below.) When the reading on the screen appears stable, make a note of the distance from the measuring point to the pressure port on the probe and hold CR (ENTER) down until screen 149 appears. After screen 149 appears, the probe can be moved.

NOTE: If the distance from the water surface to the bottom of the well is less than the range of the transducer, place the probe at the bottom of the well. This is necessary because the probe cannot be submerged to the 90 -percent depth. In shallow-well situations, placement of the probe at the bottom of the well may cause the displayed readings to be less than 90 percent. 
MOVE PROBE TO A KNOWN POSITION

GIVING A READING NEAR $90 \%$

HOLD CR WHEN STABLE

PROBE - NN.N PERCENT *

IS THIS VALUE OK $\mathrm{Y} / \mathrm{N}$ ?

The value read from the probe that will be used for the high-range calibration point appears on the screen above. If it was the most frequently occurring reading from the previous screen, press $Y$ to accept it and proceed to screen 145. If it does not represent the typical value read on screen 148 , press $N$ to allow a retry of screen 148 . 


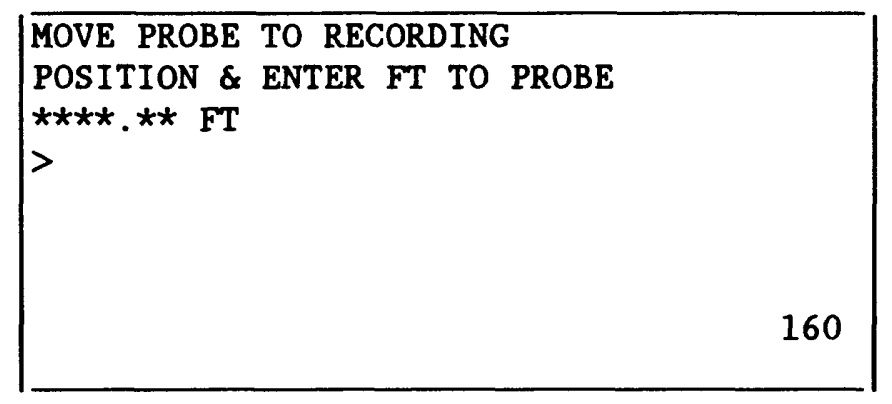

Anchor the probe in the position that will be used for the next recording period. Carefully note the distance from the measuring point to the pressure port on the probe, in feet (RECORDING POSITION). Enter this value on the above screen. The asterisks above the prompt indicate that 4 digits can be entered for the feet, followed by a decimal point and 2 digits for hundredths of a foot. Errors made during the entry can be corrected by using the left-arrow key $(\leftarrow)$. The entry is terminated by CR (ENTER). Screen 161 is the next screen to be displayed. 
MOVE PROBE TO RECORDING

POSITION \& ENTER FT TO PROBE

$\star \star \star * \star * *$ FT

NNNN.NN FT

OK $\mathrm{Y} / \mathrm{N}$ ?

161

If the value for the distance from the measuring point to the recording position is correct, then enter $Y$ to proceed to screen 162 . If it is incorrect, enter $N$ to allow the value to be reentered on screen 160 . 


\begin{tabular}{|lll|}
\hline ENTER TAPE DOWN READING & \\
IF DES IRED & & \\
$\star * * * . * *$ FT & TYPE N IF NO & \\
$>$ & & 162 \\
\end{tabular}

The distance from the measuring point to the water surface, as measured by taping down the we11 (TAPE-DOWN READING), can be entered if the user desires. The number entered will appear in the header of the data record. This value is not used by the retriever or recorder in any way. The asterisks above the prompt indicate that four digits can be entered for feet, followed by a decimal point and two digits for hundredths of a foot. Errors made during the entry can be corrected by using the left-arrow key ( $\leftarrow)$. The entry is terminated by CR (ENTER). If the user does not want to enter this value, $\mathbf{N}$ should be pressed. This will cause a tape-down reading of 0000.00 to be entered in the header. Screen 163 is the next screen to be displayed. 


\begin{tabular}{|lll|}
\hline ENTER TAPE DOWN READING & \\
IF DESIRED & TYPE N IF NO \\
$\star \star * * . * *$ & & \\
NNNN.NN & & \\
OK? Y/N? & 163 \\
& \\
\hline
\end{tabular}

The tape-down entry made on the previous screen (162) is displayed. If it is correct, press $Y$ to proceed to screen 164 . If is is incorrect, press $\mathrm{N}$ and screen 162 will reappear, allowing the tape-down reading to be reentered. 
PRESSURE FT=NNNN.NN *

FT TO WATER-NNNN.NN

TAPE DOWN =NNNN.NN

IS ALL OK Y/N?

164

The present water level is displayed using the calibration just completed or using the factory calibration, if requested. Both the distance from the measuring point to the water surface (FT TO WATER) and the feet of water over the transducer (PRESSURE FT) are displayed. The tape-down reading entered on screen 162 is shown also. The water-level display is updated each time the asterisk blinks. It may take 10 seconds for the first waterlevel reading to appear, as the probe needs time to warm up. If the displayed values are satisfactory, press $Y$ to proceed to screen 165 . If they are in error, press $N$ to allow the calibration process to be repeated (screen 140).

NOTE: If the PRESSURE FT reading is correct and the FT TO WATER reading is in error, this indicates that the probe position entry made on screen 160 was incorrect. The sum of the PRESSURE FT reading and the FT TO WATER reading will be equal to the distance from the measuring point to the pressure port on the probe (RECORDING POSITION). 


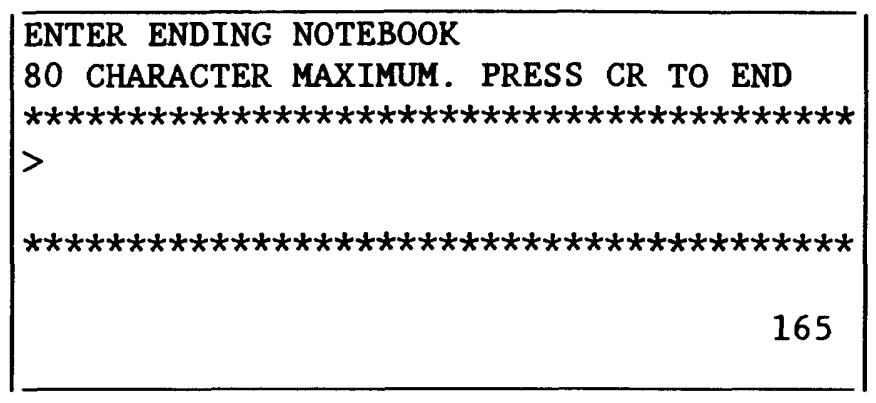

Enter any ending notes. Letters and numbers may be, used. A CR (ENTER) ends the entry. The maximum message length is 80 characters with the space available outlined by the asterisks on the screen. The DEL/BKSP key may be used to back up and correct typing errors made during the entry. The entry made will appear as the ending notes in the header of the record that is about to be collected. Screen 166 is the next screen to be displayed. 


\begin{tabular}{|l|}
\hline ENTER ENDING NOTEBOOK \\
80 CHARACTER MAXIMUM. PRESS CR TO END \\
$* * * * * * * * * * * * * * * * * * * * * * * * * * * * * * * * * * * * * *$ \\
THE ENDING MESSAGE TYPED APPEARS IN THIS \\
SCREEN AREA. \\
$* * * * * * * * * * * * * * * * * * * * * * * * * * * * * * * * * * * * * * *$ \\
OK Y/N?
\end{tabular}

If the ending notes displayed on this screen are correct, press $Y$ to proceed to screen 170 . If incorrect, press $N$ to allow reentry of the notes on screen 165 . 
IF YOU DO NOT WANT TO COLLECT THE DATA

IN THIS R200, STRIKE 'ESC'

OTHERWISE USE CR

WARNING-'ESC' WILL DESTROY ALL OF THE DATA IN THE R200

Pressing CR (ENTER) will cause screen 171 to appear while the header items and data in the R200 are transferred to a data file in the retriever. If for some reason the data are not to be collected, the user strikes 'ESC'. This will cause the data-collection process to be skipped and screen 174 will appear.

CAUTION: If the data are not collected, they will be destroyed either when the batteries are changed or when the R200 is restarted for collection of a new data record.

If the R200 contains good data, they must be collected now. The 'ESC' option is useful for preventing collection of bogus records when testing an R200 or installing a new R200.

NOTE: If this is a new installation of an R200 or if the R200 batteries have just been changed, the user should strike 'ESC' because no data record is present in the $\mathrm{R} 200$. 


\section{BUSY}

WRITING HEADER TO FILE

171

The header information in the retriever and the R200 is being transferred to a data file. No entries are to be made. Screen 172 is the next screen to be displayed. 


\begin{tabular}{|l|}
\hline BUSY \\
WRITING DATA TO FILE \\
DATA POINTS=NNNN \\
\\
\end{tabular}

Data are being transferred from the R200 to a data file in the retriever. Data are sent one line at a time, with each line consisting of several data points. Each time a line is received, the number of data readings transferred is written on the screen. Observe this number to see if the amount of data received is reasonable for the length of the record being collected. One day's data record is equal to one data point. When the record is stopped and data retrieval is requested, the $R 200$ records a partial average of the hourly readings for that day. No entries are made for this screen, and it will end when all of the data have been transferred. Screen 173 is the next screen to be displayed. 


\begin{tabular}{|ll|}
\hline DISPLAY RECORD ON SCREEN & \\
$\mathrm{Y} / \mathrm{N} ?$ & \\
& \\
& 173 \\
\hline
\end{tabular}

A11 of the data have been received and placed into a data file. The user has the option of displaying the data on the screen by pressing $Y$, or not displaying the data by pressing $N$. 
CHANGE R200 BATTERIES

RETRIEVER WILL TURN OFF

USE POWER SWITCH RESTART

PRESS Y WHEN READY

If this is a new installation of an R200 or if the R200 batteries do not need to be changed, then press $Y$ immediately.

If the batteries need to be changed, now is the time to change them because no data are in the R200. The batteries are designed to last 1 year. If 1 year will be exceeded before another station visit, replace the batteries. A good set of batteries must be kept in the R200 because a11 of the data will be destroyed if the batteries run down. This screen will display for 15 seconds, and then the retriever will turn itself off to conserve its batteries while the R200 batteries are being changed. Disconnect the R200 from the I200 and change the R200 batteries. After the R200 batteries are changed, reconnect the retriever and press the power-on switch. This screen will appear once again. Now press $\mathrm{Y}$ to continue to the next screen. 


$$
\begin{aligned}
& \text { ENTER STARTING NOTEBOOK } \\
& 80 \text { CHARACTER MAXIMUM. PRESS CR TO END }
\end{aligned}
$$

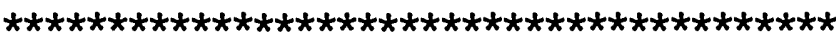

$$
\begin{aligned}
& >
\end{aligned}
$$

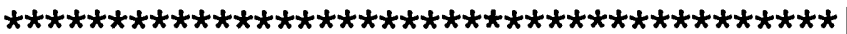

Type in any starting notebook notes. Letters and numbers may be used. A CR (ENTER) ends the entry. The maximum message length is 80 characters, with the available space outlined by the asterisks on the screen. The DEL/BKSP key may be used to back up and correct typing errors made during the entry. The typed message will appear as the starting notebook entry in the header of the next record that will be collected when the recorder is started again. This message will be stored in the R200 and collected as the start header on the next station visit. Screen 176 is the next screen to be displayed. 
ENTER STARTING NOTEBOOK

80 CHARACTER MAXIMUM. PRESS CR TO END

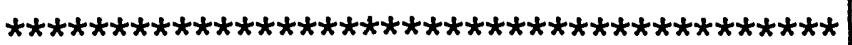

THE STARTING MESSAGE JUST TYPED APPEARS

IN THIS SCREEN AREA.

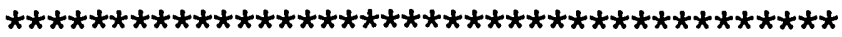
OK Y/N?

If the starting message is correct as shown, press $Y$ to proceed to screen 177. If it is incorrect, press $\mathbf{N}$ and screen 175 will reappear, allowing reentry of the starting notes. 


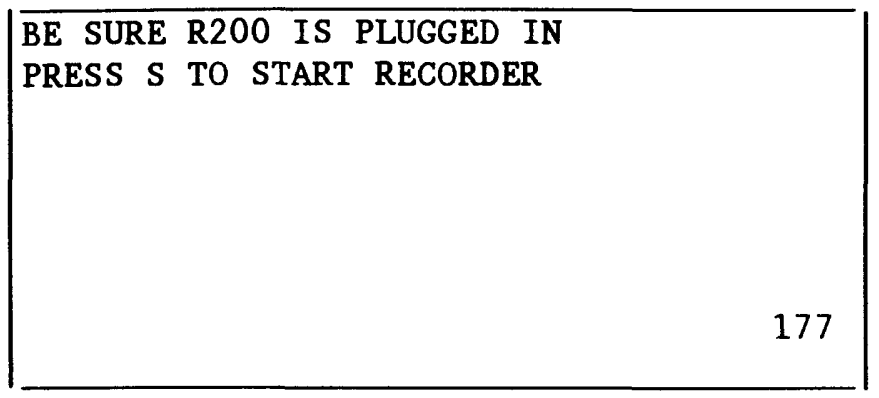

Everything has been programmed. When the user is ready for the recorder to start, press $S$. The time and the header information will be sent to the R200 and the recording process will begin. Screen 178 will be displayed while this occurs. 


\begin{tabular}{|ll|}
\hline STARTING RECORDER & \\
& 178 \\
\hline
\end{tabular}

This screen appears while the new header and the time are sent from the retriever to the $\mathrm{R} 200$. This takes about 15 seconds. After the header is sent, the recording process is started and screen 180 is displayed. 


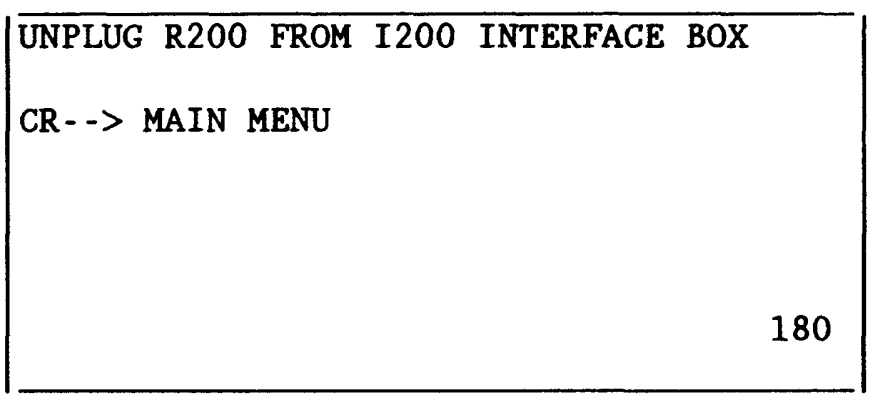

Disconnect the R200 from the $I 200$ interface box and press CR (ENTER). If desired, the interface can be disconnected from the retriever. Make sure the probe is disconnected first.

Termination of the probe functions was requested in screen 100. Disconnecting the R200 at other times could cause errors. 


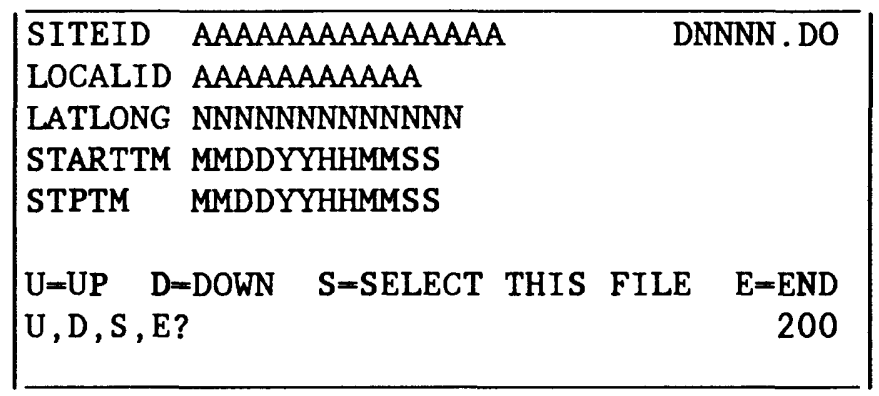

When requested to display, print, or erase a data file, this screen appears to allow the selection of the particular file. The number at the top-right corner, preceded by the letter $D$ or $B$, is the name of the file in the retriever. The letter ' $D$ ' indicates a new data file, and the letter ' $B$ ' indicates a backup data file. To aid in identifying the file, the site ID, local ID, latitude and longitude, starting time (month, day, year, hours, minutes, seconds), and stopping time (month, day, year, hours, minutes, seconds) are shown. Select U, D, S, or E as follows:

$U$ Press $U$ to cause the retriever to scan upward in data-file numbers. The number at the top right of the screen will advance as the retriever searches for a file. When a file is found, the number stops advancing, and the site ID, local ID, latitude and longitude, and the starting and stopping times are displayed along with the prompts $U, D, S$, and $E$. A maximum of 50 main (D-type) and 50 backup (B-type) data files exists. The file scanned after B0050 is D0001. File B0001 is scanned following file D0050. The files are scanned in a loop.

D Press D to scan downward in data-file numbers. The result is like U, except for the direction of the scan. This time the file scanned after D0001 is B0050. File D0050 is scanned following file B0001.

S Press $\mathbf{S}$ to select the file described on the screen for display, printing, or erasing. The exact action depends upon which operation was requested earlier on screen 003 .

E Press $E$ to end the file-selection mode without selecting any file. This will return the user to the main menu (screen 003). 


\begin{tabular}{|llll|}
\hline 1 & BEGINNING CAL & S1-NNNNNN & Z1-NNNNN \\
& & S2-NNNNNN & Z2-NNNNN \\
2 & END CAL & S1-NNNNNN & Z1-NNNNN \\
& & S2-NNNNNN & Z2-NNNNN \\
3 & FACTORY CAL & S-100000 & Z-10000 \\
& & & \\
$1,2,3 ?$ & & & 201 \\
\hline
\end{tabular}

A11 data in the $\mathrm{R} 200$ are stored in an uncalibrated form; that is, the uncorrected transducer readings are stored. When a calibration is performed, a set of coefficients is determined. These coefficients are used in equations that translate the uncalibrated data into calibrated form for display on the screen or printer. Two span coefficients (S1 and S2) and two zero coefficients ( $Z 1$ and 22 ) are used in these equations. One set of coefficients is calculated during the in-well calibration procedure just before the beginning of the data record when the R200 is installed. These are shown in the screen above as the BEGINNING CAL $\mathrm{S} 1, \mathrm{Z1}, \mathrm{S} 2$, and $\mathrm{Z2}$. A second set of coefficients is calculated during the in-well calibration procedure just before the data record is retrieved. These are listed in the above screen as the END CAL S1, Z1, S2, and Z2. The third item in the menu above shows $S=100000$ and $Z=10000$. These are the values assumed when no in-we11 calibration is made and represent the value for a normal probe (factory calibration). Select 1, 2, or 3 to display the data as follows:

- Press 1 to use the coefficients found during the in-well calibration procedure done just before data collection began. The data will be displayed, using these beginning coefficients.

- Press 2 to use the coefficients found during the in-well calibration procedure done just before the record was retrieved.

- Press 3 to use the coefficients that represent the normal probe (factory calibration). 
PRESS C TO CONTINUE DATA

PRESS S TO STOP DATA

USE E TO END DISPLAY

RETVER 02

This screen indicates that a data file is to be displayed. The first line of the file is shown (RETVER 02).

The header values are displayed first followed by the data. To scroll through the header values, press and hold $C$. Releasing $C$ stops the scroll. After the data have started to be displayed, the scroll will continue automatically until $\mathrm{S}$ is pressed to stop the scroll. To continue the scrolling of data, press $C$. The user may have to hold down these keys a short time because they will only work when the cursor reaches the end of a line.

Column 1 of the data display shows the displacement of the data from the beginning of the record, and the remaining columns show data values.

Press $E$ at any time to end this data display and return to the main menu (screen 003). 


\begin{tabular}{|lll|}
\hline 1 & HUNTER REPORTER \\
2 & RADIO SHACK \\
3 & OTHER PRINTER \\
4 & SET OTHER PRINTERS BAUD \& PARITY ETC \\
5 & RETURN TO MAIN MENU & \\
$1,2,3,4,5$ & $?$ \\
& & 300 \\
\hline
\end{tabular}

The user presses a number to tell the retriever which type of printer is attached for the data printout. The selections are described below:

- Press 1 if the Husky Hunter Reporter printer is being used. This automatically sets the printout for 40 columns. Other communications parameters are set as follows: Baud rate $=4800$, word length - 8 bits, parity = none, no. of stop bits $=1$, XON/XOFF enablement - enabled.

- Press 2 if using the Radio Shack TRP 100 printer. The printout width is automatically set for 80 columns. Other communications parameters are set as follows: Baud rate $=600$, word length $=7$, parity = ignore, no. of stop bits $=1$, XON/XOFF enablement enabled.

- Press 3 to select some other type of printer. The communications parameters and column width will be set to values previously saved in the retriever memory when item 4 on this screen was used to establish them. If the parameters for the printer being used have not been set previously, menu item 4 should be selected first.

- Press 4 to set up various printer parameters for a new printer to be used. If this has been done before, it is not necessary to do it again because the printer parameters are saved in the retriever memory. Selecting 4 will cause the retriever to display screen 301 , which is used to select the printer column width. Following screen 301, five unnumbered screens appear that are used to set the communications parameters. These parameters are described in the manufacturer's operating manual for the retriever. A brief explanation is given under screen 301.

- Press 5 to cancel the request for a data printout and to return to the main menu (screen 003). 


$\mid$\begin{tabular}{|llll}
\hline 1. & 40 & COLUMN & \\
2. & 80 & COLUMN & \\
1 OR & 2 & $?$ & \\
& & & 301 \\
\hline
\end{tabular}

Press 1 if using a 40-column printer. Press 2 if using an 80 - or greater than 80 -column printer. After the user selects 1 or 2 , the following unnumbered screen appears:

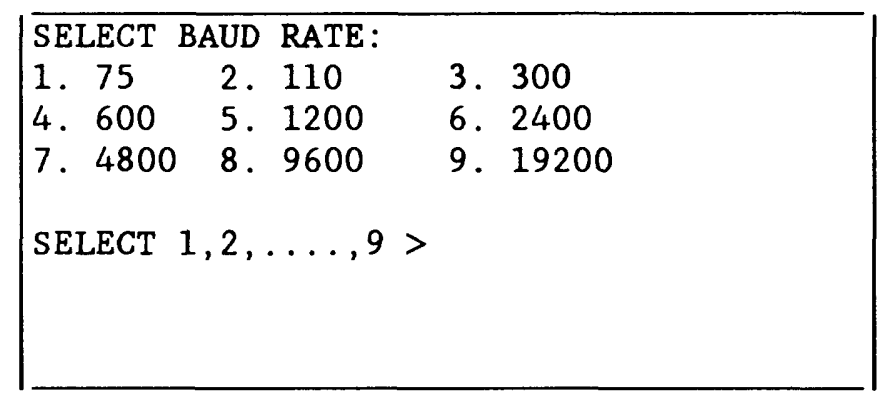

The user should press the number corresponding to the baud rate of the printer being used. After making this selection, the following unnumbered screen appears:

SELECT WORD LENGTH:
6,7, OR 8 BITS
SELECT 6,7, OR $8>$

(Screen 301 explanation continues on the next page.) 
Screen 301 (continued)

The user selects the word length, which is the number of binary bits that make up one "word" in the printer being used. After making this selection, the following unnumbered screen appears:

\begin{tabular}{l}
\hline SELECT PARITY SETTING: \\
$O=$ ODD $\quad$ E = EVEN \\
I = IGNORE $\quad$ N $=$ NONE \\
CHOOSE O,E, I, OR N $>$
\end{tabular}

The user selects the parity setting to be used when printing data files on the "OTHER PRINTER" (selected on screen 300). After making this selection, the following unnumbered screen appears:

NUMBER OF STOP BITS :

1 OR $2 ?>$

The user selects the number of stop bits to be appended to each word sent to the printer when printing data files on the "OTHER PRINTER" (selected on screen 300 ). After making this selection, the following unnumbered screen appears:

XON/XOFF ENABLEMENT:
E = ENABLE $\quad$ D $=$ DISABLE
SELECT E OR D >

The user strikes "E" or "D" to enable or disable the use of the XON/XOFF protocol when communicating with the printer. After making this selection, screen 300 reappears. 


\begin{tabular}{|llll|}
\hline 1 & BEGINNING CAL & S1-NNNNNN & Z1-NNNNN \\
& & S2-NNNNNN & Z2-NNNNN \\
2 & ENDING CAL & S1-NNNNNN & Z1-NNNNN \\
& & S2-NNNNNN & Z2-NNNNN \\
3 & FACTORY CAL & S-100000 & Z-10000 \\
4 & RAW HEX DATA & & \\
$1,2,3,4 ?$ & & & 302 \\
\hline
\end{tabular}

A11 data in the R200 are stored in an uncalibrated form; that is, the uncorrected transducer readings are stored. When a calibration is performed, a set of coefficients is determined. These coefficients are used in equations that translate the uncalibrated data into a calibrated form for display on the screen or printer. Two span coefficients (S1 and S2) and two zero coefficients ( $Z 1$ and $\mathrm{Z2}$ ) are used in these equations. One set of coefficients is found during the in-we11 calibration procedure, just before the beginning of the data record, when the R200 is installed. These are shown in the screen above as the BEGINNING CAL S1, Z1, S2, and Z2. A second set of coefficients is found during the in-we11 calibration procedure just before the record is pulled. These are 1isted in the above screen as the END CAL S1, Z1, S2, and Z2. The third item in the menu above shows $S=100000$ and $\mathrm{Z}=10000$. These are the values assumed when no in-we11 calibration is made and represent the value for a normal probe (factory calibration). The fourth menu item is used to print the data in its uncorrected form in hexadecimal format. The user selects $1,2,3$, or 4 to print the data as follows :

- Press 1 to use the coefficients found during the in-we11 calibration procedure done just before data collection began. These data will be printed or displayed using these beginning coefficients.

- Press 2 to use the coefficients found during the in-we11 calibration procedure done just before the record was retrieved.

- Press 3 to use the coefficients that represent the normal probe (factory calibration).

- Press 4 to print the data in hexadecimal format without any corrections. This displays the data as it is stored in the R200. This selection is used mainly to diagnose problems in a system that has malfunctioned. 
GET PRINTER READY

POWER ON, PAPER READY

PRESS CR TO BEGIN PRINTING

Get the printer ready. Check the paper and ribbon supply. Make sure the power is on and the cable is properly connected. Press CR (ENTER) to begin printing. 


\begin{tabular}{|ll|}
\hline TO STOP PRINT PRESS E & \\
& \\
& 304 \\
\hline
\end{tabular}

The data to be printed are being sent to the printer. If the printing process needs to be stopped for any reason, press and hold E until screen 306 appears. Some printers may continue to print for a short time after the retriever quits sending data. 


\begin{tabular}{|ll}
\hline TURN PRINTER OFF - - PRESS CR TO EXIT & \\
& \\
& 305
\end{tabular}

The printout is complete. Remove the printed copy and turn off the printer to conserve the printer battery. Press CR (ENTER) to return to the main menu (screen 003). 
The printout was stopped as requested. Remove printed output and turn off the printer power. Press CR (ENTER) to return to the main menu (screen 003). 


\begin{tabular}{l}
\hline ALL BACKUP FILES WILL BE ERASED. \\
MAIN FILES WILL BE DUMPED \\
AND RENAMED AS BACKUPS. \\
\\
IS THIS OK? Y/N?
\end{tabular}

A dump of the main data files has been requested. These main data files will be dumped in the R200 raw-data format. Before dumping the main data files, the present backup files are deleted. The main data files are renamed to become the new backup files after being dumped to the Prime computer. These new backup files are then dumped to the Prime minicomputer. If no valuable information is in the current backup files, press $Y$. This causes screen 410 to appear. If something of value might be left in the current backups, press $\mathrm{N}$ to abort.

CAUTION: Once the backups are deleted, they are gone forever. If deletion is aborted by pressing $N$, the infornation from the backups can be recovered by requesting "Dump backup files to PRIKE" on the main menu (screen 003). 


\begin{tabular}{|lll|}
\hline NEXT, DO THE FOLLOWING: \\
1 & LOGIN TO PRIME \\
2 & ENTER THE PRIMOS EDITOR (ED) \\
3 & ENTER THE INPUT MODE \\
4 & TYPE ESC WHEN READY FOR DATA & \\
& & \\
PLUG RETRIEVER INTO PRIME-CR TO BEGIN & \\
& & \\
\end{tabular}

Connect the retriever to a Prime computer terminal line. The screen above lists the steps to be performed manua11y. Press CR (ENTER) to begin the procedure.

1. After the CR (ENTER) is pressed, the retriever goes into a terminalemulation mode. If the user is unable to login on the minicomputer, the communications parameters may be set wrong. To correct, press ESC to end the terminal-emulation mode and cause screen 402 to appear. Enter $\mathrm{N}$ in response to screen 402. This will cause screen 003 to appear, and the user can reselect the option to dump main files or backup files to Prime and try the operation once again. The communications parameters can then be changed by selecting item 1 on screen 410. Suggested settings for the Prime follow, but these may vary with different systems:

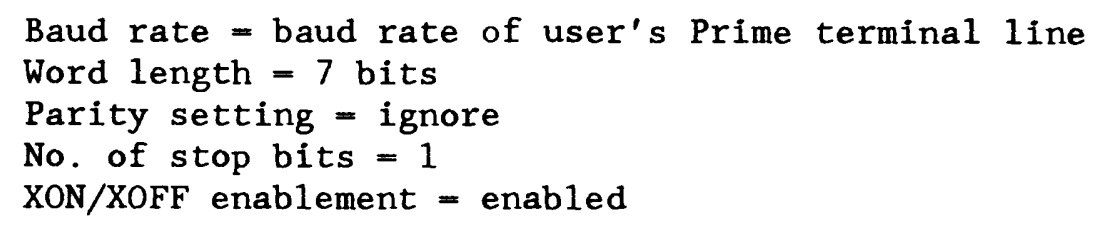

If in doubt of a setting, note the setting used on the terminal on the Prime line and try that setting. Contact the responsible system operator if the problem is not resolved. After the communications parameters are set, try logging in on the Prime. If login is not successful, have the RS-232 wiring checked.

2. When login is successful, enter the Primos editor by pressing ED.

3. Make sure the editor is in the input mode. The word INPUT should be displayed on the screen.

4. Press ESC when ready for the data transfer. Use ESC to end this screen if the above steps were unsuccessful. Pressing the ESC causes screen 402 to appear. 


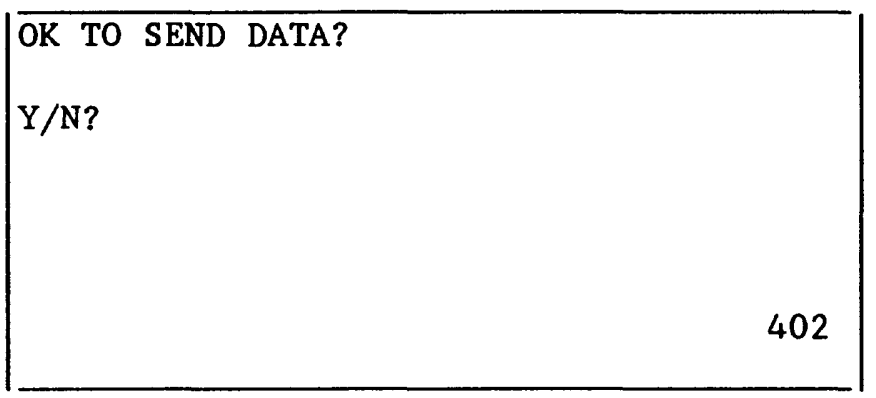

If the user has requested a dump of the main data files to the Prime, then pressing $Y$ will cause the retriever to send the data files to the Prime computer. Screen 403 will appear while the retriever sends the data files to the Prime. If the user has requested a dump of the backup data files to the Prime in R200 data format, screen 403 will appear while the files are being sent. If the user has selected to dump the backup files to the Prime in either WRD standard format or daily value card-image format, screen 406 will appear before each file is dumped to the Prime. Screen 406 allows the user to select the calibration to be applied to the data.

If login to the Prime or invoking the Primos editor input mode was unsuccessful, pressing $N$ will abort the data transmission. The main menu (screen 003) will then be displayed. 
SENDING :

SITEID AAAAAAAAAAAAAAA

LOCALID AAAAAAAAAAA

LATLONG NNNNNNNNNNNNN

STARTTM MMDYYRHRMNSC

STPTM MMDYYRHRMNSC

DATA POINTS SENT-NNNNNN

FILE-DNNNN . DO

A

$\sqrt{10}$

DATA POINTS SENT-NNNNNN 403

This screen appears as the retriever sends data to the Prime. The data file being sent is described by the site identification, local identification, latitude and longitude, starting time, and stopping time. On the bottom line are the number of data points that have been sent. This number is updated each time a line of data is transferred. The user makes no entries on this screen. When the transmission is complete, screen 404 will appear. 


\begin{tabular}{|ll|}
\hline DO THE FOLLOWING: \\
1 IGNORE ANY DATA THAT MAY BE DISPLAYED \\
2 LEAVE THE EDIT INPUT MODE(CR) \\
3 FILE DATA IN A NEWFILE(FILE NEWNAME) \\
4 LOGOUT \\
5 USE ESC TO END \\
USE CR TO BEGIN
\end{tabular}

\begin{abstract}
A11 of the data now reside in the Primos editor. This screen lists the steps to follow when the retriever terminal mode is invoked again. Press CR (ENTER) to begin. Some data left in the retriever buffer will be shown on the screen when the terminal mode is first invoked. Ignore these data. After these data have stopped, press CR (ENTER) to end the Primos editor input mode. The Primos editor should respond with the word EDIT. File the data into a Prime file by typing: FILE NEWNAME, where NEWNAME is the name the user wishes to assign to the Prime file.

GAUTION: Using an already existing file nawe will cause that file to be overwritten with these data. No warning message will appear, so be careful.
\end{abstract}

The FILE command ends the editor. Logout of the Prime computer. Use ESC on the retriever to exit the terminal-emulation mode. The main menu (screen 003) will appear. The data transfer is complete, so unplug the retriever from the Prime computer. At this point, the user may want to login on the Prime with a standard terminal and examine the data to see if the transfer was successful. If a problem occurred with the transfer, try again using the "DUMP BACKUP FILES TO PRIME" selection on screen 003. 


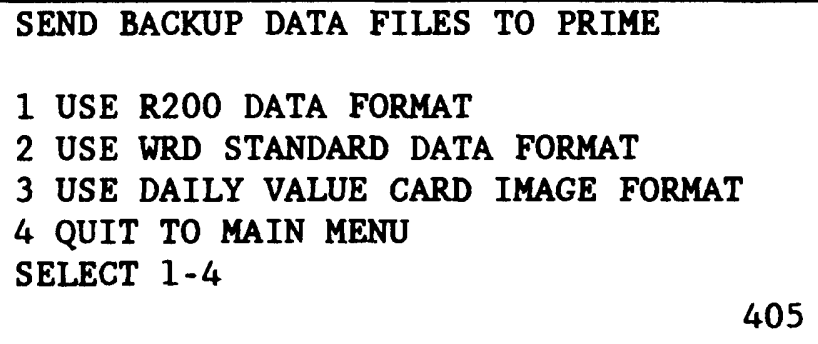

A dump of the backup data files has been requested. The user selects one of the three data formats to use in dumping the backup data to the Prime by depressing 1,2 , or 3 . If the user does not wish to dump the backup files at this time, selecting item 4 will return user to the main menu (screen 003). After the data format is selected, screen 410 appears. 


\begin{tabular}{|lll|}
\hline STATION-ID & \multicolumn{2}{c|}{ MM/DD/YY-MM/DD/YY } \\
1 BEGINNING CAL & S1-NNNNNN Z1-NNNNN \\
& S2-NNNNNN Z2-NNNNN \\
2 ENDING CAL & S1-NNNNNN Z1-NNNNN \\
& S2-NNNNNN Z2-NNNNN \\
3 FACTORY CAL & S -100000 Z =10000 \\
METHOD OF CALIBRATION 1,2,3? & 406 \\
\hline
\end{tabular}

The user selects the calibration coefficients to use in dumping this backup data file to the Prime. The backup file that will be dumped is identified by the station identification and the starting and ending times for the data record. This information is displayed across the top line of this screen. The user presses 1,2 , or 3 to select the calibration. A message will then appear across the bottom of the screen while this backup file is being dumped to the Prime. This procedure is repeated for each of the backup files residing in the retriever. After all backup data have been dumped to the Prime, screen 404 will appear, allowing the user to file and name the data file on the Prime. 


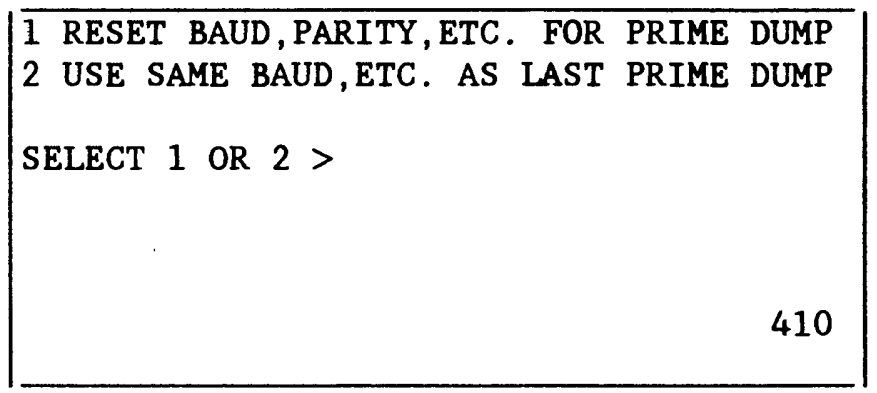

The user has requested a dump of the R200 data files to the Prime computer. If files have been dumped to the Prime previously and the user wishes to use the same communications parameters as those used for the last Prime dump, a 2 should be entered. This causes screen 411 to appear while the communications parameters are being set to the proper values. Each time that a data dump to the Prime is made, the communications parameters being used are saved in the data retriever memory. This allows the user to reselect the same parameters on subsequent Prime dumps by selecting item 2 on this screen. If the user wishes to reset the communications parameters for this Prime dump, a 1 should be entered. This causes a sequence of unnumbered screens to appear. These unnumbered screens are described under screen 301. Suggested settings for communicating with the Prime follow, but these may vary from system to system:

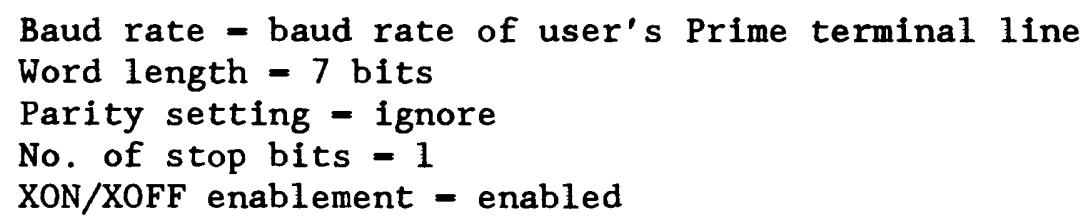

NOTE: For communications with the Prime, the baud rate selection screen only offers baud rates up through 4800 . Faster baud rates are possible when PRINTING data files. 


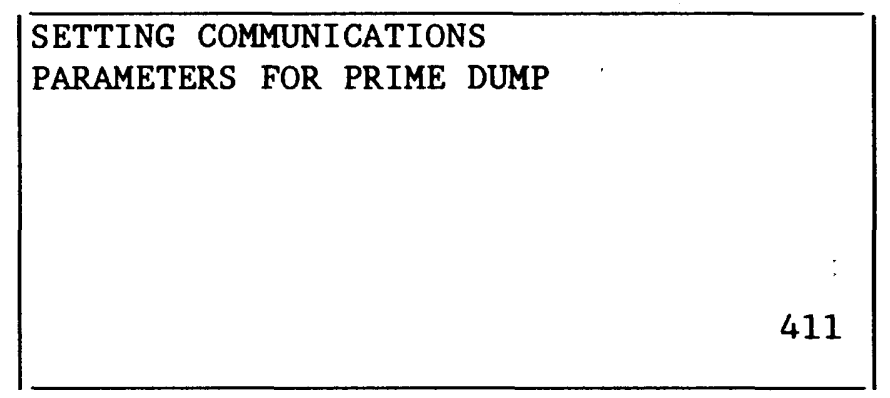

This screen appears while the communications parameters are being set for a requested data dump to the Prime computer. Screen 401 is the next screen to be displayed. 


\begin{tabular}{ll}
\hline SITEID AAAAAAAAAAAAAAA & DNNNN.DO \\
LOCALID AAAAAAAAAAA & \\
LATLONG NNNNNNNNNNNN & \\
STARTTM MMDDYYHHMMSS & \\
STPTM MMDDYYHHMSS & \\
THIS FILE WILL BE ERASED & \\
OK Y/N? & 600 \\
\hline
\end{tabular}

Erasure of a file has been requested. The file identified on the screen above is the one selected for erasure. Press Y to erase this file. If erasure is not desired, then press $N$.

CAUTION: Once a file is erased, it is gone forever. 


$$
\begin{aligned}
& \text { I/O FAILURE-CHECK } \\
& \text { PLUG CABLE BATTERY } \\
& \text { RETRY OR ABORT R/A? }
\end{aligned}
$$

E01

An I/O error occurs when the retriever fails to communicate properly with the R200, a printer, or a computer. Possible causes follow:

- The cable is not plugged into the retriever or the device with which it is communicating.

- The cable is wired improperly or is the wrong cable.

- The baud rate and other communication parameters are not set properly in the retriever or the other device. When communicating with the R200, these communication parameters are set automatically and cannot be changed.

- The batteries in the R200 are dead. The user should not change these batteries without ensuring they are dead, because al1 data will be lost when the batteries are removed. The batteries can be checked by connecting a voltmeter from pin 3 (positive) to pin 4 on the $1 / 0$ connector at the top of the battery holder. A voltage of more than 6.5 should be enough to allow communication.

- The retriever or the other device is defective. Try the retriever on something else or try another retriever if one is available.

Try correcting the problem, and then press $R$ to retry the communication. The retriever will return to a point in the program just before the communication failed. If, after several retries, communication continues to fail, the only alternative is to press A to abort the retriever program. This will turn the retriever off. The retriever can then be turned on again, and the R200 retriever program can be run from the beginning. 


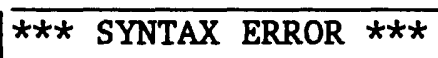

$* * *$ TRY AGAIN $* * *$

The user was asked to make an entry and made an incorrect selection. Pressing CR (ENTER) will end this screen and return the user to the screen where the error was made, allowing a retry of the entry. Some common syntax errors include entering letters where only numbers are allowed, making an illegal time-and-date entry such as specifying a month that doesn't exist, and entering the wrong number of characters. 


\begin{tabular}{|lll|}
\hline BASIC ERROR N AT LINE NNNNN & \\
RETRY OR ABORT? R/A? & & \\
& & \\
& & E03 \\
\hline
\end{tabular}

During execution of the program, an error occurred. A number (N) indicates the type of error, and the program line number (NNNNN) indicates where the error occurred. An explanation list of errors is found in the basic errors section of the retriever operations manual. Some possible errors that might occur during the operation of the retriever follow:

ERROR 7 Out-of-Memory error. This can be caused if too many files are resident in the retriever, and the retriever runs out of file space. Try erasing some files to give more space.

ERROR 11 Division by zero. This is caused by the retriever attempting to divide by zero, a math operation that cannot be performed.

ERROR 57 Too many files. See error 7 above.

Errors other than those mentioned above rarely should occur. If they do, please note the error number, line number, and specific operation being performed, and report the problem to the HIF. The occurrence of such an error could indicate a serious software bug that needs correcting or a malfunction in the retriever.

Two actions can be taken when a BASIC error occurs: Press $R$ for retry, which will cause the program to return to a screen just before the error took place so that the operation can be redone. If pressing $R$ causes the same error to occur repeatedly, the user can press A for abort, which will turn off the retriever. When the power is turned on again, the retriever program can be restarted from the program beginning. 


\begin{tabular}{|ll}
\hline ERROR SOFTWARE & \\
NOT COMPATIBLE & \\
R200 $=$ NN $\quad$ RET $=$ NN & \\
& \\
& \\
\hline
\end{tabular}

When the probe functions are selected from the main menu (screen 003), a check is made of the software version in the R200. If it is not compatible with the software in the retriever, this screen is displayed and the user cannot access any of the probe functions. If this happens, contact HIF to determine which software versions are compatible. Pressing CR (ENTER) will return the user to the main menu (screen 003). 


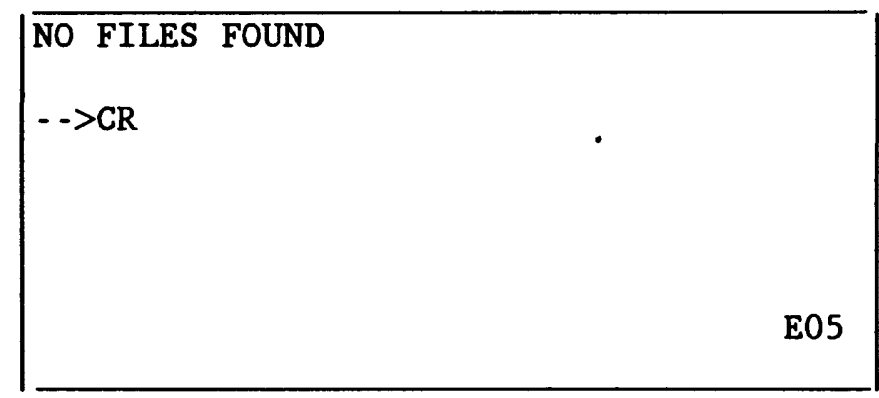

The retriever was requested to display or print a data file. However, no files existed in the retriever, and this could not be done. Pressing CR (ENTER) will return the user to the main menu (screen 003). 


\section{NO MAIN FILES EXIST}

$-->$ CR

E06

An attempt has been made to dump the main files to the Prime computer when no main files were resident in the retriever. Pressing CR (ENTER) will return the user to the main menu (screen 003). The user then may try dumping the backup files to the Prime, hoping that the desired data are located in a backup data file. The user also may view the files resident in the retriever by selecting the option to display a data file on screen 100 . 


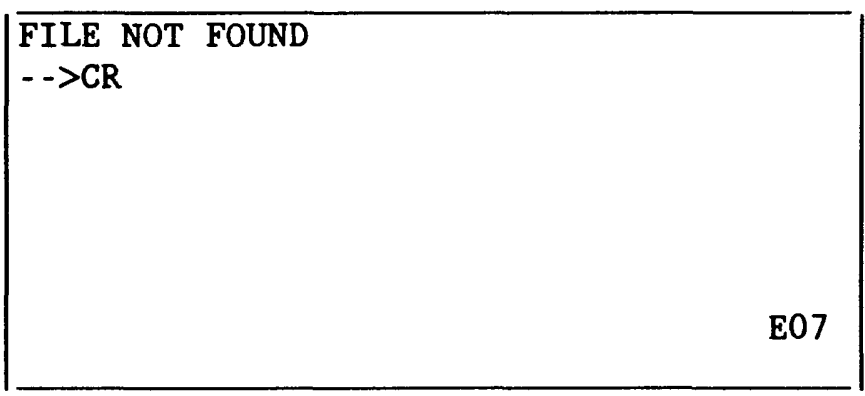

When the retriever was requested to send a file to the Prime computer, no file could be located to send. (The retriever has no data files.)

Pressing CR (ENTER) returns the user to the main menu (screen 003). 


\section{HELP WITH SPECIFIC PROBLEMS}

\section{Input-Output Failure}

If the I/O failure screen (EOI) appears, an I/O error has occurred between the data retriever and the R200. The user should attempt a retry by pressing "R." If, after one or two retries, the $I / 0$ fails, the user should check the connections between the data retriever, I200, and the R200 I/O plug. The user should then attempt a retry by pressing " $R$ " in response to error screen E01. If, after one or two tries, the I/O failure remains, try aborting the operation by pressing "A." The retriever can be turned back on, and the user can run through the retriever program to attempt the operation again. If the I/O failures continue to occur, a problem may exist with this R200 or with the I200 being used. If the I200 works properly with other R200s, this R200 has a problem and should be returned to HIF for repair.

\section{Low Batteries in Retriever}

The field person should always determine whether the retriever contains a fresh set of batteries before making a field trip to retrieve R200 data. If the retriever program gives a low-battery warning or if the retriever screen starts blanking out, the user should change the batteries in the retriever. (See manufacturer's operating instructions for the microcomputer being used as the retriever.)

\section{Retriever Program Not Running}

If the retriever program does not seem to be working and none of the screens depicted in this manual appear, the retriever program was not loaded into the microcomputer properly, or it has somehow been corrupted.

The program resides in the memory of the retriever and can be reloaded and started running again. To reload the program, the following steps should be taken:

1. Use the power switch on the retriever to turn the retriever off and then back on.

2. The retriever screen should display the TANDY operating system main menu.

3. Use the up-, down-, right-, and left-arrow keys to place the cursor (highlight) over the file named "R200.BA". Press the ENTER key.

4. The R200 Retriever program should start running, and one of the screens depicted in this manual should appear. If this is not the case, contact the Chief, Field Service and Supply Section, HIF, for assistance. 
To order the R200 and (or) parts through the HIF-CSS, the following list is included for the user's convenience:

\section{Component}

R200 (including battery pack and probe with probe cable):

0 to $10 \mathrm{lb} / \mathrm{in}_{2}^{2}$ gage

0 to $15 \mathrm{lb} / \mathrm{in}_{2}^{2}$ gage

0 to $30 \mathrm{lb} / \mathrm{in}^{2}$ gage

R200 Battery-Pack Cable:

$25-\mathrm{ft}$

$50-\mathrm{ft}$

$100-\mathrm{ft}$

$200-f t$

Custom length--contact HIF Field Service and Supply Section
WRD Instrumentation Catalog No
5105001

5105002

5105003

5105015

5105016

5105017

5105018

5105011

5105019

Support-Line Kit

Calibration Cable:

$35-\mathrm{ft}$

5105025

$70-\mathrm{ft}$

5105026 
Data Retriever Carrying Case/Fieldman's Kit

5105006

Case containing the following accessories:

170 -foot calibration cable

1 support-1ine kit

1 alcohol-wash bottle

1 expendable-supplies refill kit

$$
\text { (see below) }
$$

Note: Case has room to carry all the items

normally needed to service the R200

Expendable-Supplies Refill Kit:

30 desiccants in watertight container

10 replacement 0 -rings

1 tube 0 -ring lubricant

20 spare screws for battery-pack hanger

(No. 8-32 x 5/16 in.-1ong stainless-steel pan head)

5 spare bottle caps

\section{Data Retriever:}

The portable computer used as the $\mathrm{R} 200$ data retriever

is not offered by the HIF. This unit must be supplied by the user. Contact HIF for instructions on downloading the R200 retriever program. 